\title{
mHealth technology for ecological momentary assessment in physical activity research: a systematic review
}

\author{
Rafael Zapata-Lamana ${ }^{\text {Equal first author, } 1 \text {, Jaume F Lalanza }}{ }^{2}$, Josep-Maria Losilla ${ }^{3}$, Eva Parrado ${ }^{2}$, Lluis Capdevila ${ }^{\text {Corresp. Equal }}$ \\ first author, 2 \\ 1 Escuela de Educación, Universidad de Concepción, Los Ángeles, Chile \\ 2 Departament of Basic Psychology, Universitat Autónoma de Barcelona, Bellaterra (Barcelona), Spain \\ 3 Departament of Psychobiology and Methodology of Health Science, Universitat Autónoma de Barcelona, Bellaterra (Barcelona), Spain \\ Corresponding Author: Lluis Capdevila \\ Email address: Iluis.capdevila@uab.cat
}

Objective: To systematically review the publications on ecological momentary assessment (EMA) relating to physical activity (PA) behavior in order to classify the methodologies and to identify the main mHealth technology-based tools and procedures that have been applied during the first ten years since the emergence of smartphones. As a result of this review we want to ask if there is enough evidence to propose the use of the term "mEMA" (mobile-based EMA).

Design: A systematic review according to PRISMA Statement. (PROSPERO registration: CRD42018088136).

Method: Four databases (PsycINFO, CINALH, Medline and Web of Science Core Collection) were searched electronically from 2008 to February 2018.

Results: A total of 76 studies from 297 potential articles on the use of EMA and PA were included in this review. It was found that $71 \%$ of studies specifically used "EMA" for assessing PA behaviors but the rest used other terminology that also adjusted to the inclusion criteria. Just over half (51.3\%) of studies (39) used mHealth technology, mainly smartphones, for collecting EMA data. The majority (79.5\%) of these studies (31 out of 39) were published during the last 4 years. On the other hand, $58.8 \%$ of studies that only used paper-and-pencil were published during the first 3 years of the 10-year period analyzed. An accelerometer was the main built-in sensor used for collecting PA behavior by means of mHealth (69\%). Most of the studies were carried out on young-adult samples, with only 3 studies in older adults. Women were included in $60 \%$ of studies, and healthy people in $82 \%$. The studies lasted between 1 and 7 days in $57.9 \%$, and between 3 and 7 assessments per day were carried out in $37 \%$. The most popular topics evaluated together with PA were psychological state and social and environmental context.

Conclusions: We have classified the EMA methodologies used for assessing PA behaviors. A total of 71\% of studies used the term "EMA" and 51.3\% used mHealth technology. Accelerometers have been the main built-in sensor used for collecting PA. The change of trend in the use of tools for EMA in PA coincides with the technological advances of the last decade due to the emergence of smartphones and mHealth technology. There is enough evidence to use the term mEMA when mHealth technology is being used for monitoring real-time lifestyle behaviors in natural situations. We define mEMA as the use of mobile computing and communication technologies for the ecological momentary assessment of health and lifestyle behaviors. It is clear that the use of mHealth is increasing, but there is still a lot to be gained from taking advantage of all the capabilities of this technology in order to apply EMA to PA behavior. Thus, mEMA methodology can help in the monitoring of healthy lifestyles under both subjective and Peer) reviewing PDF | (2019:09:41586:2:0:CHECK 21 Feb 2020) 
objective perspectives. The tendency for future research should be the automatic recognition of the physical activity of the user without interrupting their behavior. The ecological information could be completed with voice messages, image captures or brief text selections on the touch screen made in real time, all managed through smartphone Apps. This methodology could be extended when EMA combined with mHealth are used to evaluate other lifestyle behaviors. 


\section{2 mHealth technology for ecological momentary}

\section{3 assessment in physical activity research: a systematic}

\section{4 review.}

5 Rafael Zapata Lamana ${ }^{1,2}$, Jaume F Lalanza ${ }^{2}$, Josep-Maria Losilla ${ }^{3}$, Eva Parrado Romero², Lluis

6 Capdevila ${ }^{2}$

7

$8 \quad{ }^{1}$ Escuela de Educación, Universidad de Concepción, Los Ángeles, Chile

92 Departament of Basic Psychology, Universitat Autònoma de Barcelona (UAB), Spain

$10{ }^{3}$ Departament of Psychobiology and Methodology of Health Science, Universitat Autònoma de 11 Barcelona (UAB), Spain

12

\section{Corresponding Author:}

14 Lluis Capdevila ${ }^{2}$

15 School of Psychology, Universitat Autònoma de Barcelona, 08193 Bellaterra (Barcelona) Spain

16 Email address: 1luis.capdevila@uab.cat 


\section{Abstract}

20 Objective: To systematically review the publications on ecological momentary assessment 21 (EMA) relating to physical activity (PA) behavior in order to classify the methodologies and to

22 identify the main mHealth technology-based tools and procedures that have been applied during the first ten years since the emergence of smartphones. As a result of this review we want to ask if there is enough evidence to propose the use of the term "mEMA" (mobile-based EMA). Design: A systematic review according to PRISMA Statement. (PROSPERO registration: CRD42018088136).

Method: Four databases (PsycINFO, CINALH, Medline and Web of Science Core Collection) were searched electronically from 2008 to February 2018.

Results: A total of 76 studies from 297 potential articles on the use of EMA and PA were included in this review. It was found that $71 \%$ of studies specifically used "EMA" for assessing PA behaviors but the rest used other terminology that also adjusted to the inclusion criteria. Just over half $(51.3 \%)$ of studies (39) used mHealth technology, mainly smartphones, for collecting EMA data. The majority (79.5\%) of these studies (31 out of 39 ) were published during the last 4 years. On the other hand, $58.8 \%$ of studies that only used paper-and-pencil were published during the first 3 years of the 10-year period analyzed. An accelerometer was the main built-in sensor used for collecting PA behavior by means of mHealth (69\%). Most of the studies were carried out on young-adult samples, with only 3 studies in older adults. Women were included in $60 \%$ of studies, and healthy people in $82 \%$. The studies lasted between 1 and 7 days in $57.9 \%$, and between 3 and 7 assessments per day were carried out in 37\%. The most popular topics evaluated together with PA were psychological state and social and environmental context. Conclusions: We have classified the EMA methodologies used for assessing PA behaviors. A total of $71 \%$ of studies used the term "EMA" and 51.3\% used mHealth technology. Accelerometers have been the main built-in sensor used for collecting PA. The change of trend in the use of tools for EMA in PA coincides with the technological advances of the last decade due to the emergence of smartphones and mHealth technology. There is enough evidence to use the term mEMA when mHealth technology is being used for monitoring real-time lifestyle behaviors in natural situations. We define mEMA as the use of mobile computing and communication technologies for the ecological momentary assessment of health and lifestyle behaviors. It is clear that the use of mHealth is increasing, but there is still a lot to be gained from taking advantage of all the capabilities of this technology in order to apply EMA to PA behavior. Thus, mEMA methodology can help in the monitoring of healthy lifestyles under both subjective and objective perspectives. The tendency for future research should be the automatic recognition of the physical activity of the user without interrupting their behavior. The ecological information could be completed with voice messages, image captures or brief text selections on the touch screen made in real time, all managed through smartphone Apps. This methodology could be extended when EMA combined with mHealth are used to evaluate other lifestyle behaviors. 
60

61

62

63

64

65

66

67

68

69

70

71

72

73

74

75

76

77

78

79

80

81

82

83

84

85

86

87

88

89

90

91

92

93

94

95

96

97

98

99

100

101

102

\section{Introduction}

Physical inactivity is a leading cause of death worldwide. It is considered a pandemic in the $21 \mathrm{st}$ century (1) and is more prevalent in developed countries (2). Unfortunately, despite the consensus on the benefits of physical activity (PA), the levels of sedentary lifestyle have increased worldwide (3). Regular PA of moderate intensity should be promoted for the entire population in order to reduce the risk of suffering many health disorders, such as cardiovascular disease, type 2 diabetes, Alzheimer's disease or depression (4), and to achieve substantial health benefits (5).

In this context, an important problem is to unify the research methodology so that scientific evidence can be recognized. On the one hand, PA is often assessed by weekly self-reports (6). The main limitation of these studies is that they are based on retrospective assessments which can lead to a recall bias (7). Thereby errors could occur due to overestimation and underestimation of PA (8). In addition, these assessments are subjective estimations by the participants, thus reliability and validity could be highly affected (9). On the other hand, there are objective methods available with greater reliability, such as accelerometry, GPS positioning, heart rate monitoring and movement sensors. But studies using these methods generally report PA values without examining contextual co-variables (10). In fact, some studies tend to not taken in account the temporal influences (11) nor the individual characteristics (12). In order to solve these problems, the objective measures could be matched with self-reports in real time regarding the context of PA.

In this sense, Ecological Momentary Assessment (EMA) (13) is a suitable methodology which enables studies to be conducted in order to analyse lifestyle experiences in real-time, in realworld settings, over time and across contexts. EMA is based on monitoring or sampling strategies to assess phenomena at the moment they occur in natural settings. Thus, from the original proposal of this methodology, "Ecological" means that the data are captured in the natural environment of the subjects; "Momentary" means that assessments focus on current feelings and behaviours, rather than concentrating on recall or summary over long periods of time; and "Assessment" means that multiple assessments are collected over time to provide a profile for behaviour throughout time (7). A good contribution to EMA methodology has been a checklist for reporting EMA studies (CREMAS) in nutrition and PA among young people (14). However, this checklist becomes very demanding for describing published studies that, in general terms, comply with the basic features of the EMA methodology. For instance, in a recent systematic review using CREMAS to assess sedentary behavior in articles published between 2007 and 2017, only 21 of 50 potential studies were included. It is surprising that only four of these works were combining EMA with objective measurement like accelerometry (15), since those 10 years is when the massive appearance of smartphones took place worldwide. Since the emergence of the first mobile phone in the 70's, and from the emergence of the first applications (apps) for iOS and Android operating systems around 2008, smartphones have rapidly evolved. The improvement in fast processors, small and long-lasting batteries, large memory capacity and very precise built-in sensors has paved the way for apps that are now affecting our lifestyle (16). Thus, in the last years, we are talking about mobile health (mHealth) when we are using some of the smartphone capabilities for assessing or monitoring health or lifestyle (17). More specifically, the term mHealth has been defined as "the use of mobile computing and 
103

104

105

106

107

108

109

110

111

112

113

114

115

116

117

118

119

120

121

122

123

124

125

126

127

128

129

130

131

132

133

134

135

136

137

138

139

140

141

142

communication technologies in health care and public health" (18). For example, you can use the camera of a smartphone to capture images for assessing dietary intake (19); or mobile phone's built-in motion sensors and self-report through the touch screen for measuring PA (20). Existing systematic reviews of EMA interventions focus on specific age groups such as young people $(9,14)$; or about aspects of the lifestyle other than the PA, such as emphasizing sedentary behavior (15); or are based on an excessively strict list of criteria that does not include all EMA studies according to their original definition $(14,15)$.

Our objective is to systematically review the scientific publications on EMA relating to physical activity (PA) behavior in order to classify the methodologies and to identify the main mHealth technology-based tools and procedures that have been applied during the first ten years since the emergence of smartphones. As a result of this review we want to ask if there is enough evidence to propose the use of the term "mEMA" (mobile-based EMA) when mHealth technology is being used together with the EMA methodology for monitoring lifestyle behaviors such as PA, in real time and in natural environments.

\section{METHODOLOGY}

The study was undertaken in accordance with the Preferred Reporting Items for Systematic Reviews and Meta-Analyses (PRISMA) statement (21) A systematic review protocol had previously been registered in the PROSPERO repository with the code: CRD42018088136 (22).

\section{Search strategy}

A systematic review of the literature was performed using the following databases and portals according to the order indicated: PsycINFO by PsycNET, CINAHL by EBSCOhost, MEDLINE by PubMed, and Core Collection of Web of Science by Web of Science. Our aim was to identify studies that used EMA methodologies to measure PA in participants of all ages. The search comprised the period between 2008 and 2018 because we were interested in analyzing the use of mHealth technology to evaluate PA behavior. This is because mHealth solutions are based on applications for smartphones (apps) and we have already commented that the first apps appeared around 2008. According to Liao et al (14), an increasing number of studies on PA have adopted EMA due to methodological advances in mobile technologies in recent years. Thus, we consider that before 2008 smartphones or tablets still did not have enough capable built-in sensors for allowing EMA.

When possible, keywords and terms were obtained from Thesaurus. The search strategy followed the guidelines from Peer Review of Electronic Search Strategies (PRESS) (23). The searching general syntax was: ("Ecological momentary assessment" OR "experience sampling" OR "experience samplings") AND (Exercise OR Exercises OR "Physical activity" OR "physical activities"), and it was adapted to each database (the specific search syntaxes are provided in a supplementary file). 


\section{Study selection and inclusion criteria}

144 No exclusion criteria were applied for gender, age or clinical condition, but as regards the

145 language, only full-text articles in English or Spanish were reviewed. Reviews, editorials, 146 protocols and theses were not included. The articles selected by title and abstract met the 147 conditions indicated in Table 1. EMA could be applied to PA or to other variables, but then PA 148 has to be assessed by other methodologies and compared to the main EMA variable.

149

150

151

152

153

154

155

156

157

158

159

160

161

162

163

164

165

166

167

168

169

170

171

172

173

174

175

176

177

178

179

180

181

182

*** Include Table 1 here $* * *$

\section{Data extraction}

In a first step, duplicate articles from the four databases were deleted using Mendeley. One reviewer (RZ) applied the inclusion/exclusion criteria to all titles and abstracts. Articles meeting the inclusion criteria were selected and when decisions could not be made from the title and abstract alone, the full paper was also retrieved. The selected papers were checked independently by two review authors (RZ, JFL). Discrepancies were resolved through discussion (with a third author where necessary, LC) until reaching consensus. A standardized, pre-piloted form was used to extract data from the included articles in order to assess the study quality and for the synthesis of the evidence. Extracted information included: general information (author, year, country); sample (size, population, age, etc.); details of tools used (measure, purpose/use, type of tool, etc.); methodological protocol (experimental design, response rate, time interval required to completion, and mode of administration, sensor use, etc.) as well as assessing the main variables. Furthermore, the data extraction was carried out by two reviewers (RZ, JFL).

\section{Risk of bias assessment tools}

The tool proposed by National Institute for Health and Care Excellence (NICE) for prognostic studies (24) was applied by two reviews (RZ, JFL) to assess the risk of bias (RoB) of the selected non-experimental studies. Following the same procedure, to assess the RoB of the selected experimental and quasi-experimental studies we applied the "Cochrane Risk of Bias Tool for Randomized Trials" (25) and the "Risk Of Bias In Non-randomized Studies - of Interventions" (ROBINS-I) (26), respectively. Since the aim of the systematic review was not to analyze the obtained results, the following items were removed: from NICE 1.3 ("the prognostic factor of interest is adequately measured in study participants, sufficient to limit potential bias") and 1.6 ("the statistical analysis is appropriately accounted for, limiting potential bias with respect to the prognostic factor of interest"); from Cochrane "Selective Reporting" and "Other Bias"; and from ROBINS-I "Bias in measurement of outcomes" and "Bias in selection of the reported result".

\section{Strategy for data synthesis}

We provide a narrative synthesis of the findings from the included studies structuring it around the methods and the procedure related to EMA in PA research. The main information is also 
183 showed in the Tables. In the Discussion, an analysis is made on the combination of EMA and

184

185

186

187

188

189

190

191

192

193

194

195

196

197

198

199

200

201

202

203

204

205

206

207

208

209

210

211

212

213

214

215

216

217

218

219

220

221

222

mHealth technology and some suggestions are given for future researchers in order to standardize the application of this mobile-based methodology for monitoring PA behaviors.

\section{RESULTS}

\section{Literature Search}

Figure 1 shows the flow diagram of systematic reviews for analysis of studies proposed by PRISMA. After the duplicate records in databases were excluded, a total of 297 potential studies as regards EMA in PA were identified. The eligibility criteria were applied and the analysis was made by reading the title and the abstracts. During the selection phase, all discrepancies between the two reviewers were resolved by consensus without requiring a third reviewer. Finally, 74 articles were considered for this review for the qualitative synthesis of the data. In fact, a total of 76 studies were analyzed because two of those 74 articles contained 2 studies with each one with different samples.

*** Include Figure 1 here ***

\section{Studies characteristics with EMA in PA}

Table 1 described the inclusion criteria for this review. In our systematic review, we identified 54 of 76 studies (71\%) that specifically used "EMA" for assessing PA behaviors. But there were $29 \%$ studies that used other terminology that also adjusted to the inclusion criteria. Thus, we identified studies that used "Experienced Sampling Method" (ESM) $(33,39,52,57,79,91,99,101,102)$ for referring to a similar methodology. We also found other terms used in a similar way, like "Ambulatory Assessment" was used in 6 studies $(36,61-$ $63,97,98)$, with "Naturalistic Study", only used in 1 study (35). Finally, we found 5 studies that applied a similar methodology without specifically naming it $(27,59,66,77,95)$.

The publication date of articles ranged between 2008 and 2018. With 19.7\% of articles being published between 2008 and 2011,39.5\% between 2012 and 2015, and 38.2\% between 2016 and 2018. When clustering the studies geographically, $63.2 \%$ of these were performed in North America (including the USA), $34.2 \%$ in Europe, $5.3 \%$ in Asia and $1.3 \%$ in Oceania, with the USA being the country with the highest publication rate (56.6\%). The majority of studies included both males and females, with a total number of 13.663 participants ( $60.2 \%$ females). As regards the characteristics of the participants (Table 2), $25 \%$ of studies were carried out with children and adolescents (9-17 years), with a total number of 8543 participants (55.7\% females). On the one hand, $26.3 \%$ of studies were carried out with university students, with a total number of 1388 participants (67.4\% females), and an age range between 18 and 28 years. On the other hand, $44.7 \%$ of studies were carried out with 3585 adult participants ( $69.8 \%$ females), an age range between 18 and 59 years, with heterogeneous characteristics (patients, healthy subjects, active, inactive, recreational runners, etc.). Only 3 studies (3.9\%) were carried out with 147 older adult participants ( $49.7 \%$ females), with an age range between 60 and 73 years. As regards the 
223

224 225

226

227

228

229

230

231

232

233

234

235

236

237

238

239

240

241

242

243

244

245

246

247

248

249

250

251

252

253

254

255

256

257

258

259

260

261

262

designs of the studies, $92.1 \%$ used a longitudinal prospective design. Only 5 studies (6.6\%) used a randomized-experimental design and only 1 study used a quasi-experimental design.

*** Include Table 2 here***

\section{Characteristics of the main methodological aspects about EMA.}

The detailed characteristics of the main methodological aspects about EMA in PA are presented in Table 3 . As regards the study duration, $57.9 \%$ of studies were performed between 1 and 7 days, $25 \%$ of studies were performed for a duration of 1-2 weeks. Six studies (7.9\%) were performed for a duration of 3-4 weeks, and another 7 studies (9.2\%) took longer than 1 month. In relation to the daily period, $46.1 \%$ of studies performed measurements all day $(46.1 \%)$ and $10.5 \%$ of studies took measurement for only half a day. An individualized time of collection was used in $32.9 \%$ of studies, taking into account the timetable of each participant (for example, studies with children sample avoided the school time). Only 10.5\% of studies did not report any daily measurement. As regards the frequency of the measurements during a day, $36.8 \%$ of studies used 3 to 7 prompts per day, 22.4 of studies used 8 to 12 prompts per day, $21.1 \%$ used more than 13 prompts per day, $15.8 \%$ used 1 to 2 prompt per day. Only in 3 studies (3.9\%) participants were asked to complete the EMA immediately after a target event (based on event). According to column "Use the name EMA" in Table 3, 71\% of studies used the EMA expression for naming the main methodology, with 13.2\% of studies using "Experienced Sampling Method" (ESM), and 7,9\% used "Ambulatory Assessment". Only 1 study used the expression "Naturalistic Study", and the rest (6.6\%) did not use any specific nomenclature to name the methodology of the study.

As regards the recording system for data collection, 39 studies (51.3\%) used mHealth technology (mainly smartphones), 18 studies (23.7\%) used PDAs (personal digital assistant, also known as a handheld PC), 18 studies (23.7\%) used the most traditional system of paper and pencil, and only 2 studies (2.6\%) used an online survey system. A large majority (79.5\%) of the studies (31 of 39) were published during the last 4 years of the 10-year period analyzed between 2014 and February 2018 . On the other hand, $76.5 \%$ of the studies that only used paper and pencil to collect EMA data were published before 2014, and 58.8\% during the 3 first years of the 10-year period analyzed between 2008 and February $2010(29-31,53,54,56,79,101,103,104)$. For its part, 11 of 18 studies $(61.1 \%)$ that only used PDAs were published during the middle years of the 10-year period analyzed between 2011 and $2015(28,34,52,58,64,77,80,96,98,105)$.

As regards the sensors for collecting data (see column "EMA sensors" in Table 3), the accelerometer was used in 39 studies (51.3\%), and 27 of these studies used the accelerometer built-in to the smartphone as an own sensor (mHealth technology). Two of them used the accelerometer combined with GPS using mHealth technology. Only 1 study used GPS only (with mHealth), and the rest of studies did not use any sensor to collect data. $81.5 \%$ of studies using mHealth with accelerometers were published between 2014 and 2018. The rest of the studies that recorded PA with accelerometry but not with mHealth technology (12 studies) used conventional 
263 accelerometers for the study combined with PDA, paper and pencil, and online survey

264 recordings. Only 1 study used a cardiac chest band for recording heart rate with mHealth.

265 Finally, it was found 25 studies did not use mHealth nor accelerometry, and $64 \%$ of them were

266 published between 2008 and 2013.

267

268

*** Include Table 3 here***

269

270

Target variables analyzed in the studies

271

Some studies reported other target variables in addition to PA, even if they were not registered

272 under EMA protocols. Figure 2 shows these complementary target variables, which included,

273 among others, psychological state, body mass index (BMI), or contextual, social and dietary

274 variables.

275

276

*** Include Figure 2 here***

277

278

279

Risk of bias assessment

280

NICE tool was applied to assess the RoB of $92.1 \%$ of studies ( 70 longitudinal prospective studies), the Cochrane tool was applied to 5 experimental studies (6.6\%), and ROBINS-I tool

281 was applied to 1 quasi-experimental study. Figure 3 shows a summary of the results of RoB 282 assessment.

283 About half of the longitudinal prospective studies were evaluated as high RoB in three NICE 284 criteria (representativeness, outcome adequately measured and potential confounders appropriately controlled for), and $29 \%$ of studies did not provide enough information about loss to follow-up of participants and/or the amount of missing data. Half of the experimental and

288

289

290

291

292

293

294 quasi-experimental studies showed a high RoB regarding the allocation concealment of participants and the amount of missing data in the outcome measure, and half of the studies did not provide enough information about this last RoB.

\section{*** Include Figure 3 here***}

\section{DISCUSSION}

The aim of this study was to systematically review the scientific publications on EMA relating to

295

296 physical activity (PA) behavior in order to classify the methodologies and to identify the main mHealth technology-based tools and procedures that have been applied during the first ten years since the emergence of smartphones. We have found enough evidence to use the term mEMA (mobile-based EMA) when mHealth technology is being used together with the EMA methodology for monitoring lifestyle behaviors such as PA, in real time and in natural environments. A total of 76 studies (in 74 articles) on the use of EMA and PA were included for 301 the synthesis. The majority of studies were carried out on healthy adults, lasted around one week 
302

303

304

305

306

307

308

309

310

311

312

313

314

315

316

317

318

319

320

321

322

323

324

325

326

327

328

329

330

331

332

333

334

335

336

337

338

339

340

341

and applied mHealth technology (39 studies, 51.3\%), mainly using smartphones and accelerometers.

\section{EMA, mHealth and mEMA.}

The term EMA means ecological momentary assessment and was proposed before 2000 (13). We identified $71 \%$ of the studies that specifically used "EMA" for assessing PA behaviors. This results indicate that the term EMA is mostly accepted by the scientific community in the field of PA, but that there are some authors who do not use EMA to refer to the same concept. In this sense, the recent proposal of a checklist for reporting EMA studies (CREMAS) in nutrition and PA (14) has become very interesting. However, as we have already commented, this checklist becomes very demanding when you want to describe some published studies that, in general terms, comply with the basic features of the EMA methodology. We did not use this checklist because we were interested in identifying studies that have used EMA or similar basic procedures since the emergence of smartphones on the market.

In this sense, we identified half of the reviewed studies (51.3\%, 39 studies) using mHealth technology; that is, they mainly used smartphones for collecting EMA data. This coincides with the technological advances of the last decade due to the emergence of smartphones and mHealth technology. Thus, in the first years, the studies that did not use any technology to collect data predominated and most were based on paper and pencil (P\&P) self-reports. When smartphones were in full swing but were not yet powerful enough to collect and process multiple data in real time, PDAs predominated. In fact, PDAs were also known as handheld PCs and were small computers that made the collection of user self-reports easier than P\&P. The improvement was that it allowed EMA records to be more environmentally friendly than the P\&P system. In fact, if more objective data were to be collected, accelerometers were also used ( 6 of 18 studies using PDAs).

Finally, in the most recent years the emergence of mHealth technology in the field of research on PA and health is most noticeable. This has been possible thanks to the rapid evolution and expansion of both smartphones and applications (Apps). Current smartphones have much faster processors than PCs 10 years ago and are capable of monitoring lifestyle behaviors using multitasking tools. This improvement, along with small and long-lasting batteries has enabled the recordings to have multiple and very precise built-in sensors (16) and use the smartphone capabilities to be synchronized for assessing or monitoring health or lifestyle $(17,18)$.

In other systematic reviews on the application of EMA in PA behavior, only one study used a combination of technology for the EMAs in nutrition and PA among young people (14), and only 3 studies with adults combined EMA with mobile phones and accelerometers (15). In our systematic review, much less restrictive with the concept of EMA, the main built-in sensor used for collecting PA behavior with smartphones was the accelerometer (27 of 39 studies using mHealth). Only 3 studies used GPS $(35,89,90)$ and only 1 study used a cardiac chest band for recording heart rate to collect objective data related to PA (37). Only 3 of these studies used the combination of 2 sensors $(37,89,90)$. In short, it is clear that the use of mHealth is increasing, but 
342 there is still a long way to make the most of the capabilities of this technology for applying EMA 343 to PA behavior.

344 Thus, based on our systematic review, we have found enough evidence to firmly propose the use 345 of the term mEMA (mobile-based EMA) when mHealth technology is being used together with 346 the EMA methodology, although this term had already been used previously (94). More 347 specifically, we agree with defining mEMA as "the use of mobile computing and communication 348 technologies for the ecological momentary assessment of health and lifestyle behaviors". As an 349 example, some researchers have combined mHealth and EMA methodologies to study alcohol, tobacco and drugs consumption (106), depression and anxiety (107), eating disorders and obesity (108), or nutrition and PA behaviors (109). Thus, mEMA methodology can facilitate monitoring

352

353

354

355

356

357

358

359

360

361

362

363

364

365

366

367

368

369

370

371

372

373

374

375

376

377

378

379

380

381

of healthy lifestyles under both subjective and objective perspectives, using tools such as written diaries or self-reports on a touch screen, messages on social networks, and motion or physiological sensors, all managed through smartphone apps $(7,110)$.

\section{Profile of the populations studied with EMA and PA}

The selected studies included heterogeneous samples from children to older adults, men and women, healthy and clinical participants. Regarding the age of the participants, the studies were carried out on young-adult samples, including children and adolescents (25\%), university students $(26 \%)$ and adults $(45 \%)$. In general, this variety of population age is receptive to the use of new technologies like smartphones as well as using this technological advance daily

$(111,112)$. This fact could explain the high rate of technology used for EMA assessments in our review (76.3\%). Conversely, only 3 studies were found using EMA and PA in older adults $(39,61,63)$. Studies in the elderly are an important challenge for science, due to the increase in life expectancy (113). Thus, we encourage scientists to incorporate older adults and elderly samples in the future EMA projects. It has been pointed out that older people are reluctant to participate in studies that promote electronic forms of data collection (114). However, technology is becoming an increasingly used strategy in health research (115), because, among other reasons, it may offer a great level of accuracy in PA research using EMA (116). Thereby, mHealth research has the capability to adapt the advances in technologies to elderly and overcome the initial rejection. In fact, the 3 studies found with older adults used smartphones and accelerometers $(61,63)$, and only one of them reported difficulties with the battery management and the size of the response scales on the screen (39). It is noteworthy that the average age of the participants in the two studies without technological issues was $60.1 \pm 7.1$, which is not even considered old population in most countries; whereas the average age was $68.7 \pm 5.5$ years in the only study with few technological difficulties, which could be considered pre-old age (117). This fact could explain the positive acceptance of technology by the older adult samples analyzed in the 3 selected studies.

As regards gender, we found more studies carried out with women (60\%) rather than men. Previous literature has indicated that women could be more adherent than men to participate in research projects and this could be a possible explanation for the gender differences found (118).

PeerJ reviewing PDF | (2019:09:41586:2:0:CHECK 21 Feb 2020) 
382 Interestingly, in general women were less likely to participate in both PA and exercise behaviors 383 (119). Therefore, future EMA and PA studies should take into account possible gender

384

385

386

387

388

389

390

391

392

393

394

395

396

397

398

399

400

401

402

403

404

405

406

407

408

409

410

411

412

413

414

415

416

417

418

419

420

421 differences and it should continue working along this line, seeking gender equality in scientific studies, as part of the RRI framework (Responsible, Research, Innovation) (120). As regards health status, most participants were considered healthy and only 14 studies (18\%) included samples with both a physiological or psychological clinical condition. For the latter, the most common were mood disorders. In this sense, current studies show possible relationships between mood disorders and PA. In detail, PA has been presented as a good complemental therapeutic strategy to reduce stress, alleviate depression symptoms and enhance psychological states (121). Thus, EMA methodology could contribute to further explain the relationship between psychological states and PA engagement. In addition, the main topic that accompanied PA in healthy samples was "affect and emotions" (Fig. 2), highlighting the influence of PA on psychological states.

\section{Study designs used in EMA and PA, and methodological aspects.}

An interesting result from the reviewed studies corresponds to the research designs. This systematic review shows that $92 \%$ of the studies followed a longitudinal prospective design, while only $7 \%$ of them followed an experimental design, and $1 \%$ a quasi-experimental design (Table 2). Hence, increasing the amount of experimental designs could help in determining cause-effect relationships as regards PA and other variables like mental states in future studies. As regards the duration of the EMA assessments, the range was from one day (62) up to 12 months (38). The majority of the studies lasted between 1 and 7 days (58\%). From this result, it is suggested to increase the duration of the future studies using EMA in order to determine longterm habits. However, a limitation of extended longitudinal studies could be an increase in the number of dropouts (122). This is known as attrition concern can lead to the subsequent biases of auto-selection and experimental survival (123). In other words, participants who reported all EMA assessments throughout a very long study could have different individual characteristics from those who not complete all the study. It was then checked whether studies showing a high Risk of Bias related to loss to follow-up were those with longer duration, without finding significant results. Therefore, we suggest a duration between 1 and 4 weeks as an optimal balance between habits information and low levels of dropout for future EMA studies.

In relation to the within-day intervals for EMA assessments, 35\% of the studies established EMA assessments throughout the whole day, whereas $32 \%$ scheduled the assessments according to the availability of the participants; for example, studies with children samples avoided school hours (81). Interestingly, only $26 \%$ of studies were to found directly differentiate between workingdays and non-working days. The comparison of working days and non-working days enables possible patterns of physical activity depending on the type of day to be studied (124). Finally, in our systematic review there is a great variety in the range of the number of assessments per day. Between 3 and 7 assessments per day were carried out in $37 \%$ of studies, followed by 8 to 12 per day (22\%) and 1 to 2 per day (16\%). We recommend between 3 to 7 assessments per day. In this 
422 context, it has been published that excessive prompts or requests for EMA surveys could

423

424

425

426

427

428

429

430

431

432

433

434

435

436

437

438

439

440

441

442

443

444

445

446

447

448

449

450

451

452

453

454

455

456

457

458

459

460

461

increase the number of lost responses, or it could cause participants to respond randomly (125).

\section{Topics associated with the research in EMA and PA.}

The main topic (omitting demographic data) that accompanied PA was psychological state (Fig 2), which is a global variable that includes: affection, emotions, depression, stress or anxiety. This is interesting due to the high rates of mental disorders in the general population worldwide (126) and the positive relation between PA practice and mental health. General activity (as well as BMI) was the second topic studied along with PA. It is related to everyday behaviors like active transport, watching TV or eating. These behaviors are important to understand the lifestyle of the participants and their possible motives and barriers for PA practice (124).

Finally, some stable anthropometric variables like BMI have been assessed in 35 studies (46.1\%), although they have not been evaluated by EMA, demonstrating the importance of PA behavior in relation to overweight and obesity (127).

\section{Limitations}

Our systematic review is pioneer in examining mHealth application for EMA studies in the field of PA, though there are some limitations. First, it was not possible to report on the adherence levels to EMA in the participants of most of the studies, because the methodological strategies for reporting EMA data collection were diverse. Similar information has been reported by Liao et al (14) in a systematic review on the use of EMA on diet and PA in young population, highlighting the heterogeneity in the EMA data collection methods. We encourage researchers to incorporate results on adherence to EMA interventions as well as the number of dropouts. Although mHealth technologies can help to provide objective EMA recordings, they also have some difficulties. For instance, the high cost of development and maintenance for mHealth Apps, the lack of standardization, data management, technical problems, slow connections, and so on are possible problems that should be borne in mind (128). In addition, mEMA devices could be expensive if they are only used for research purposes.

\section{Future research directions.}

mHealth technology could be of great help to apply EMA strategies in developing countries (129), since it reduces the costs compared to a traditional intervention (130). A few years ago, specific and expensive sensors like isolated accelerometers were used to investigate PA behaviors.

We encourage researchers to require participants to use their own devices instead of providing specific research instruments to take advantage of the increasing ability of smartphones for synchronously monitoring different objective parameters $(16,17,18)$. This should be the current trend in research on healthy lifestyles like PA behavior. Smartphone Apps and sensors (mHealth technology) allow the concept of mEMA to be accepted, especially in relation to PA. It is ideal to use built-in sensors or other sensors easily connected by Bluetooth for monitoring the 
462 duration, frequency and intensity of PA. Thus, built-in sensors like accelerometer, GPS, altimeter

463 or gyroscope can provide continuous information about PA running in background while the user 464 performs their daily activities. Or you can also add simultaneous parameters from other external 465 sensors connected via Bluetooth, such as cardiorespiratory information using thoracic bands or 466 other wearables. The tendency should be the automatic recognition of the user activity without 467 interrupting their behavior, based on machine learning algorithms. The ecological information 468 could be completed with voice messages, image captures or brief text selections on the touch 469 screen made in real time. Current mobile devices already have the ability to process all this 470 information, but it will be necessary to persuade the user to carry their smartphone during the 471 whole day.

472

\section{CONCLUSIONS}

474 In our review we have classified the EMA methodologies used for assessing PA behaviors and 475 found that $71 \%$ of studies specifically used the term "EMA". Just over half $(51.3 \%)$ of studies 476 used mHealth technology, mainly smartphones, for collecting EMA data. An accelerometer was 477 the main built-in sensor used for collecting PA behavior by means of mHealth (69\%). The 478 change of trend in the use of tools for EMA in PA coincides with the technological advances of 479 the last decade due to the emergence of smartphones and mHealth technology.

480 There is enough evidence to use the term mEMA (mobile-based EMA) when mHealth 481 technology is being used together with the EMA methodology for monitoring lifestyle behaviors 482 such as PA, in real time and in natural environments. We define mEMA as the use of mobile 483 computing and communication technologies for the ecological momentary assessment of health 484 and lifestyle behaviors. It is clear that the use of mHealth is increasing, but there is still a long 485 way to make the most of this technology in order to apply EMA to PA behavior. Thus, mEMA 486 methodology can help in the monitoring of healthy lifestyles under both subjective and objective 487 perspectives. The tendency for future research should be the automatic recognition of the user's 488 physical activity without interrupting their behavior. From our review, we suggest the use of 489 mEMA methodology with experimental designs, a duration between 1 and 4 weeks as an optimal 490 balance between habits information and low levels of dropout, a number of assessments per day 491 between 3 to 7, differentiating between working days and non-working days. The ecological 492 information could be completed with synchronized information from other sensors or wearables, 493 all managed through smartphone Apps. This methodology could be extended when EMA 494 combined with mHealth are used to evaluate other lifestyle behaviors.

495

496

497 


\section{REFERENCES}

501

1. Kohl HW, Craig CL, Lambert EV, Inoue S, Alkandari JR, Leetongin G, Kalmeier S. The

502

503

504 21;380(9838):294-305.

505

506

507

508

509

510

511

512

513

514

515

516

517

518

519

520

521

522

523

524

525

526

527

528

529

530

531

532

533

534

535

536

537

538

539

2. Dumith SC, Hallal PC, Reis RS, Kohl HW. Worldwide prevalence of physical inactivity and its association with human development index in 76 countries. Prev Med (Baltim). 2011 Jul;53(1-2):24-8.

3. Booth FW, Roberts CK, Thyfault JP, Ruegsegger GN, Toedebusch RG. Role of Inactivity

in Chronic Diseases: Evolutionary Insight and Pathophysiological Mechanisms. Physiol Rev. 2017 Oct 1;97(4):1351-402.

4. Fiuza-Luces C, Garatachea N, Berger NA, Lucia A. Exercise is the Real Polypill. Physiology. 2013 Sep;28(5):330-58.

5. U.S. Department of Health and Human Services. 2018 Physical Activity Guidelines Advisory Committee Scientific Report. 2018.

6. Prince SA, Adamo KB, Hamel ME, Hardt J, Connor Gorber S, Tremblay M. A comparison of direct versus self-report measures for assessing physical activity in adults: a systematic review. Int J Behav Nutr Phys Act. 2008 Nov 6;5:56.

7. Shiffman S, Stone AA, Hufford MR. Ecological momentary assessment. Annu Rev Clin Psychol. 2008;4:1-32.

8. Shephard RJ. Limits to the measurement of habitual physical activity by questionnaires.

Br J Sports Med. 2003 Jun;37(3):197-206; discussion 206.

9. Marszalek J, Morgulec-Adamowicz N, Rutkowska I, Kosmol A. Using ecological momentary assessment to evaluate current physical activity. Vol. 2014, BioMed Research International. 2014.

10. Ainsworth B, Cahalin L, Buman M, Ross R. The Current State of Physical Activity Assessment Tools. Prog Cardiovasc Dis. 2015 Jan;57(4):387-95.

11. Bauman AE, Reis RS, Sallis JF, Wells JC, Loos RJF, Martin BW, Lancet Physical Activity Series Working Group. Correlates of physical activity: why are some people physically active and others not? Lancet (London, England). 2012 Jul 21;380(9838):25871.

12. Dunton. Ecological Momentary Assessment in Physical Activity Research. Exerc Sport Sci Rev. 2017;45(1):48-54.

13. Stone, Arthur A. Shiffman S. Ecological momentary assessment (EMA) in behavorial medicine. Ann Behav Med. 1994;16(3):199-202.

14. Liao Y, Skelton K, Dunton G, Bruening M. A Systematic Review of Methods and Procedures Used in Ecological Momentary Assessments of Diet and Physical Activity Research in Youth: An Adapted STROBE Checklist for Reporting EMA Studies (CREMAS). J Med Internet Res. 2016 Jun 21;18(6):e151.

15. Romanzini CLP, Romanzini M, Batista MB, Barbosa CCL, Shigaki GB, Dunton G, Mason T, Ronque ERV. Methodology Used in Ecological Momentary Assessment Studies About Sedentary Behavior in Children, Adolescents, and Adults: Systematic Review Using the Checklist for Reporting Ecological Momentary Assessment Studies. J Med Internet Res. 2019 May 15;21(5):e11967.

16. Ozdalga E, Ozdalga A, Ahuja N. The smartphone in medicine: a review of current and potential use among physicians and students. J Med Internet Res. 2012 Sep 27;14(5):e128. 
545 17. Fiordelli M, Diviani N, Schulz PJ. Mapping mHealth research: a decade of evolution. J

546

547

548

549

550

551

552

553

554

555

556

557

558

559

560

561

562

563

564

565

566

567

568

569

570

571

572

573

574

575

576

577

578

579

580

581

582

583

584

585

586

587

588

589

590
Med Internet Res. 2013 May 21;15(5):e95.

18. Free C, Phillips G, Felix L, Galli L, Patel V, Edwards P. The effectiveness of M-health technologies for improving health and health services: a systematic review protocol. BMC Res Notes. 2010 Dec 6;3(1):250.

19. Daugherty BL, Schap TE, Ettienne-Gittens R, Zhu FM, Bosch M, Delp EJ, Ebert DS, Kerr DA, Boushey CJ. Novel technologies for assessing dietary intake: evaluating the usability of a mobile telephone food record among adults and adolescents. J Med Internet Res. 2012 Apr 13;14(2):e58.

20. Dunton GF, Dzubur E, Kawabata K, Yanez B, Bo B, Intille S. Development of a Smartphone Application to Measure Physical Activity Using Sensor-Assisted Self-Report. Front Public Heal. 2014;2:12.

21. Liberati A, Altman DG, Tetzlaff J, Mulrow C, Gøtzsche PC, Ioannidis JPA, Clarke M, Deveraux PJ, Kleijnen J, Moher D. The PRISMA statement for reporting systematic reviews and meta-analyses of studies that evaluate healthcare interventions: explanation and elaboration. BMJ. 2009 Jul 21;339:b2700.

22. Zapata-Lamana, R.; Lalanza, J.F.; Losilla, J.M.; CAPDEVILA, L1. (2018). Methodology of ecological momentary assessment (EMA) in physical activity research: a systematic review. PROSPERO, CRD42018088136.

23. McGowan J, Sampson M, Salzwedel DM, Cogo E, Foerster V, Lefebvre C. PRESS Peer Review of Electronic Search Strategies: 2015 Guideline Statement. J Clin Epidemiol. 2016 Jul;75:40-6.

24. NICE. The guidelines manual : appendices B - I Tailored service improvement support. 2012;(November).

25. Higgins JPT, Altman DG, Gøtzsche PC, Jüni P, Moher D, Oxman AD, Savovic J, Schulz KF, Weeks L, Sterne JA, Cochrane Bias Methods Group, Cochrane Statistical Methods Group. The Cochrane Collaboration's tool for assessing risk of bias in randomised trials. BMJ. 2011 Oct 18;343:d5928.

26. Sterne JA, Hernán MA, Reeves BC, Savović J, Berkman ND, Viswanathan M, Henry D, Altman DG, Ansari MT, Boutron I, Carpenter JR, Chan AW, Churchill R, Deeks JJ, Hróbjartsson A, Kirkham J, Jüni P, Loke YK, Pigott TD, Ramsay CR, Regidor D, Rothstein HR, Sandhu L, Santaguida PL, Schünemann HJ, Shea B, Shrier I, Tugwell P, Turner L, Valentine JC, Waddington H, Waters E32, Wells GA33, Whiting PF34, Higgins JP. ROBINS-I: a tool for assessing risk of bias in non-randomised studies of interventions. BMJ. 2016 Oct 12;355:i4919.

27. Aggio D, Wallace K, Boreham N, Shankar A, Steptoe A, Hamer M. Objectively Measured Daily Physical Activity and Postural Changes as Related to Positive and Negative Affect Using Ambulatory Monitoring Assessments. Psychosom Med. 2017 Sep;79(7):792-7.

28. Basen-Engquist K, Carmack CL, Li Y, Brown J, Jhingran A, Hughes DC, Perkins HY, Scruggs S, Harrison C, Baum G, Bodurka DC, Waters A. Social-cognitive theory predictors of exercise behavior in endometrial cancer survivors. Health Psychol. 2013 Nov;32(11):1137-48.

29. Biddle SJH, Soos I, Hamar P, Sandor I, Simonek J, Karsai I. Physical activity and sedentary behaviours in youth: Data from three central-eastern European countries. Eur J Sport Sci. 2009;9(5):295-301.

30. Biddle SJH, Gorely T, Marshall SJ. Is television viewing a suitable marker of sedentary 
591

592

593

594

595

596

597

598

599

600

601

602

603

604

605

606

607

608

609

610

611

612

613

614

615

616

617

618

619

620

621

622

623

624

625

626

627

628

629

630

631

632

633

634

635

636 behavior in young people? Ann Behav Med. 2009 Oct 7;38(2):147-53.

31. Biddle SJH, Marshall SJ, Gorely T, Cameron N. Temporal and environmental patterns of sedentary and active behaviors during adolescents' leisure time. Vol. 16, International Journal of Behavioral Medicine. Biddle, Stuart J. H.: British Heart Foundation National Centre for Physical Activity and Health, School of Sport \& Exercise Sciences, Loughborough University, Loughborough, LEC, United Kingdom, LE11 3TU, s.j.h.biddle@lboro.ac.uk: Springer; 2009.p. 278-86.

32. Biddle SJH, Gorely T, Marshall SJ, Cameron N. The prevalence of sedentary behavior and physical activity in leisure time: A study of Scottish adolescents using ecological momentary assessment. Prev Med (Baltim). 2009 Feb;48(2):151-5.

33. Bohnert A, Burdette K, Dugas L, Travers L, Randall E, Richards M, Luke A. Multimethod analyses of discretionary time use and health behaviors among urban lowincome African-American adolescents: a pilot study. J Dev Behav Pediatr. 2013 Oct;34(8):589-98.

34. Bond DS, Thomas JG, Ryder BA, Vithiananthan S, Pohl D, Wing RR. Ecological momentary assessment of the relationship between intention and physical activity behavior in bariatric surgery patients. Int J Behav Med. 2013 Mar 28;20(1):82-7.

35. Bonham T, Pepper G V, Nettle D. The relationships between exercise and affective states: a naturalistic, longitudinal study of recreational runners. PeerJ. 2018;6.

36. Bossmann T, Kanning M, Koudela-Hamila S, Hey S, Ebner-Priemer U. The association between short periods of everyday life activities and affective states: a replication study using ambulatory assessment. Front Psychol. 2013;4.

37. Brannon EE, Cushing CC, Crick CJ, Mitchell TB. The promise of wearable sensors and ecological momentary assessment measures for dynamical systems modeling in adolescents: a feasibility and acceptability study. Transl Behav Med. 2016;6(4):558-65.

38. Burg MM, Schwartz JE, Kronish IM, Diaz KM, Alcantara C, Duer-Hefele J, Davidson KW. Does Stress Result in You Exercising Less? Or Does Exercising Result in You Being Less Stressed? Or Is It Both? Testing the Bi-directional Stress-Exercise Association at the Group and Person (N of 1) Level. Ann Behav Med. 2017 Dec 13;51(6):799-809.

39. Cabrita M, Lousberg R, Tabak M, Hermens HJ, Vollenbroek-Hutten MMR. An exploratory study on the impact of daily activities on the pleasure and physical activity of older adults. Eur Rev AGING Phys Act. 2017;14.

40. Conroy DE, Maher JP, Elavsky S, Hyde AL, Doerksen SE. Sedentary behavior as a daily process regulated by habits and intentions. Health Psychol. 2013 Nov;32(11):1149-57.

41. Dunton GF, Liao Y, Intille SS, Spruijt-Metz D, Pentz M. Investigating children's physical activity and sedentary behavior using ecological momentary assessment with mobile phones. Obesity (Silver Spring). 2011 Jun 16;19(6):1205-12.

42. Dunton GF, Intille SS, Wolch J, Pentz MA. Children's perceptions of physical activity environments captured through ecological momentary assessment: a validation study. Prev Med (Baltim). 2012 Aug;55(2):119-21.

43. Dunton GF, Intille SS, Wolch J, Pentz MA. Investigating the impact of a smart growth community on the contexts of children's physical activity using Ecological Momentary Assessment. Health Place. 2012 Jan;18(1):76-84.

44. Dunton GF, Liao Y, Kawabata K, Intille S. Momentary assessment of adults' physical activity and sedentary behavior: Feasibility and validity. Frontiers in Psychology. 2012 Jul; 3: 260.

Peer) reviewing PDF | (2019:09:41586:2:0:CHECK 21 Feb 2020) 
637 45. Dunton GF, Huh J, Leventhal AM, Riggs N, Hedeker D, Spruijt-Metz D, Pentz MA.

638

639

640

641

642

643

644

645

646

647

648

649

650

651

652

653

654

655

656

657

658

659

660

661

662

663

664

665

666

667

668

669

670

671

672

673

674

675

676

677

678

679

680

681

682

Momentary assessment of affect, physical feeling states, and physical activity in children. Health Psychol. 2014 Mar;33(3):255-63.

46. Dunton GF, Liao Y, Intille S, Huh J, Leventhal A. Momentary assessment of contextual influences on affective response during physical activity. Health Psychol. 2015

Dec;34(12):1145-53.

47. Dunton GF, Dzubur E, Intille S. Feasibility and Performance Test of a Real-Time SensorInformed Context-Sensitive Ecological Momentary Assessment to Capture Physical Activity. J Med Internet Res. 2016 Jun 1;18(6):e106.

48. Elavsky S, Kishida M, Mogle JA. Concurrent and lagged relations between momentary affect and sedentary behavior in middle-aged women. MENOPAUSE-THE J NORTH Am MENOPAUSE Soc. 2016;23(8):919-23.

49. Emerson JA, Dunsiger S, Williams DM. Reciprocal within-day associations between incidental affect and exercise: An EMA study. Psychol Health. 2018 Jan 2;33(1):130-43.

50. Fanning J, Mackenzie M, Roberts S, Crato I, Ehlers D, McAuley E. Physical Activity, Mind Wandering, Affect, and Sleep: An Ecological Momentary Assessment. JMIR MHEALTH UHEALTH. 2016;4(3).

51. Fortier MS, Guerin E, Williams T, Strachan S. Should I exercise or sleep to feel better? A daily analysis with physically active working mothers. Ment Health Phys Act. 2015;8:5661.

52. Fuller-Tyszkiewicz M, Skouteris H, Mccabe M. A re-examination of the benefits of exercise for state body satisfaction: Consideration of individual difference factors. J Sports Sci. 2013;31(7):706-13.

53. Gorely T, Atkin AJ, Biddle SJH, Marshall SJ. Family circumstance, sedentary behaviour and physical activity in adolescents living in England: Project STIL. The International Journal of Behavioral Nutrition and Physical Activity. 2009 Jun; 6:33.

54. Gorely T, Biddle SJH, Marshall SJ, Cameron N. The prevalence of leisure time sedentary behaviour and physical activity in adolescent boys: an ecological momentary assessment approach. Int J Pediatr Obes. 2009 Jan;4(4):289-98.

55. Hager ER, Tilton NA, Wang Y, Kapur NC, Arbaiza R, Merry BC, Black MM. The home environment and toddler physical activity: an ecological momentary assessment study. Pediatr Obes. 2017 Feb;12(1):1-9.

56. Hausenblas HA, Gauvin L, Symons Downs D, Duley AR. Effects of abstinence from habitual involvement in regular exercise on feeling states: an ecological momentary assessment study. Br J Health Psychol. 2008 May;13(Pt 2):237-55.

57. Heininga VE, van Roekel E, Wichers M, Oldehinkel AJ. Reward and punishment learning in daily life: A replication study. Brañas-Garza P, editor. PLoS One. 2017 Oct 4;12(10):e0180753.

58. Hekler EB, Buman MP, Ahn D, Dunton G, Atienza AA, King AC. Are daily fluctuations in perceived environment associated with walking? Psychol Health. 2012;27(9):1009-20.

59. Hyde AL, Conroy DE, Pincus AL, Ram N. Unpacking the Feel-Good Effect of Free-Time Physical Activity: Between- and Within-Person Associations With Pleasant-Activated Feeling States. J Sport Exerc Psychol. 2011;33(6):884-902.

60. Jones M, Taylor A, Liao Y, Intille SS, Dunton GF. Real-time subjective assessment of psychological stress: Associations with objectively-measured physical activity levels. Psychol Sport Exerc. 2017 Jul;31:79-87.

Peer) reviewing PDF | (2019:09:41586:2:0:CHECK 21 Feb 2020) 
683 61. Kanning M, Ebner-Priemer U, Schlicht W. Using activity triggered e-diaries to reveal the

684

685

686

687

688

689

690

691

692

693

694

695

696

697

698

699

700

701

702

703

704

705

706

707

708

709

710

711

712

713

714

715

716

717

718

719

720

721

722

723

724

725

726

727

728 associations between physical activity and affective states in older adult's daily living.

The International Journal of Behavioral Nutrition and Physical Activity. 2015 Sep;

12:111.

62. Kanning, Schoebi D. Momentary affective states are associated with momentary volume, prospective trends, and fluctuation of daily physical activity. 2016 May; 7:744.

63. Kanning M, Hansen S. Need Satisfaction Moderates the Association Between Physical Activity and Affective States in Adults Aged 50+: an Activity-Triggered Ambulatory Assessment. Ann Behav Med. 2017 Feb 18;51(1):18-29.

64. Kim J, Nakamura T, Kikuchi H, Yoshiuchi K, Yamamoto Y. Co-variation of depressive mood and spontaneous physical activity evaluated by ecological momentary assessment in major depressive disorder. Conf Proc . Annu Int Conf IEEE Eng Med Biol Soc IEEE Eng Med Biol Soc Annu Conf. 2014 Aug;2014:6635-8.

65. Knell G, Gabriel KP, Businelle MS, Shuval K, Wetter DW, Kendzor DE. Ecological Momentary Assessment of Physical Activity: Validation Study. J Med Internet Res. 2017 Jul 18;19(7):e253.

66. LePage ML, Crowther JH. The effects of exercise on body satisfaction and affect. Body Image. 2010 Mar;7(2):124-30.

67. LePage ML, Price M, O’Neil P, Crowther JH. The effect of exercise absence on affect and body dissatisfaction as moderated by obligatory exercise beliefs and eating disordered beliefs and behaviors. Vol. 13, Psychology of Sport and Exercise. LePage, Marie L.: Department of Psychology, Kent State University, Kent, OH, US, 44242-0001, mlepage@kent.edu: Elsevier Science; 2012.p. 500-8.

68. Liao Y, Intille S, Wolch J, Pentz MA, Dunton GF. Understanding the physical and social contexts of children's non-school sedentary behavior: An ecological momentary assessment study. Vol. 11, Journal of Physical Activity \& Health. US: Human Kinetics; 2014. p. 588-613.

69. Liao Y, Intille SS, Dunton GF. Using ecological momentary assessment to understand where and with whom adults' physical and sedentary activity occur. Int J Behav Med. 2015 Feb 18;22(1):51-61.

70. Liao Y, Chou C-P, Huh J, Leventhal A, Dunton G. Associations of Affective Responses During Free-Living Physical Activity and Future Physical Activity Levels: an Ecological Momentary Assessment Study. Int J Behav Med. 2017 Aug;24(4):513-9.

71. Liao Y, Solomon O, Dunton GF. Does the Company of a Dog Influence Affective Response to Exercise? Using Ecological Momentary Assessment to Study DogAccompanied Physical Activity. Am J Heal Promot. 2017 Sep;31(5):388-90.

72. Liao Y, Chou C-P, Huh J, Leventhal A, Dunton G. Examining acute bi-directional relationships between affect, physical feeling states, and physical activity in free-living situations using electronic ecological momentary assessment. J Behav Med. 2017 Jun 20;40(3):445-57.

73. Maher JP, Doerksen SE, Elavsky S, Conroy DE. Daily satisfaction with life is regulated by both physical activity and sedentary behavior. J Sport Exerc Psychol. 2014 Apr;36(2):166-78.

74. Maher JP, Dzubur E, Huh J, Intille S, Dunton GF. Within-Day Time-Varying Associations Between Behavioral Cognitions and Physical Activity in Adults. J Sport Exerc Psychol. 2016 Aug;38(4):423-34. 
729

730

731

732

733

734

735

736

737

738

739

740

741

742

743

744

745

746

747

748

749

750

751

752

753

754

755

756

757

758

759

760

761

762

763

764

765

766

767

768

769

770

771

772

773

774
75. Marquet O, Alberico C, Adlakha D, Hipp JA. Examining Motivations to Play Pokemon GO and Their Influence on Perceived Outcomes and Physical Activity. JMIR SERIOUS GAMES. 2017;5(4).

76. Marquet O, Alberico C, Hipp AJ. Pokémon GO and physical activity among college students. A study using Ecological Momentary Assessment. Comput Human Behav. 2018 Apr;81:215-22.

77. Mata J, Thompson RJ, Jaeggi SM, Buschkuehl M, Jonides J, Gotlib IH. Walk on the bright side: physical activity and affect in major depressive disorder. J Abnorm Psychol. 2012 May;121(2):297-308.

78. McCormick BP, Frey G, Lee C-T, Chun S, Sibthorp J, Gajic T, Stamatovic-Gajic B, Maksimovich M. Predicting transitory mood from physical activity level among people with severe mental illness in two cultures. Int J Soc Psychiatry. 2008 Nov;54(6):527-38.

79. McCormick BP, Frey GC, Lee C-T, Gajic T, Stamatovic-Gajic B, Maksimovic M. A pilot examination of social context and everyday physical activity among adults receiving Community Mental Health Services. Acta Psychiatr Scand. 2009 Mar;119(3):243-7.

80. Nadell MJ, Mermelstein RJ, Hedeker D, Marquez DX. Work and non-work physical activity predict real-time smoking level and urges in young adults. Vol. 17, Nicotine \& Tobacco Research. Nadell, Melanie J.: Institute for Health Research and Policy, University of Illinois at Chicago, 1747 W. Roosevelt Road, Chicago, IL, US, 60608, melaniejnadell@gmail.com: Oxford University Press; 2015. p. 803-9.

81. O'Connor SG, Koprowski C, Dzubur E, Leventhal AM, Huh J, Dunton GF. Differences in Mothers' and Children's Dietary Intake during Physical and Sedentary Activities: An Ecological Momentary Assessment Study. J Acad Nutr Diet. 2017 Aug;117(8):1265-71.

82. Pickering TA, Huh J, Intille S, Liao Y, Pentz MA, Dunton GF. Physical Activity and Variation in Momentary Behavioral Cognitions: An Ecological Momentary Assessment Study. J Phys Act Health. 2016 Mar;13(3):344-51.

83. Rouse PC, Biddle SJH. An ecological momentary assessment of the physical activity and sedentary behaviour patterns of university students. Health Educ J. 2010 Mar;69(1):11625.

84. Rusby JC, Westling E, Crowley R, Light JM. Psychosocial correlates of physical and sedentary activities of early adolescent youth. Health Educ Behav. 2014 Feb 2;41(1):4251 .

85. Sala M, Brosof LC, Rosenfield D, Fernandez KC, Levinson CA. Stress is associated with exercise differently among individuals with higher and lower eating disorder symptoms: An ecological momentary assessment study. Int J Eat Disord. 2017 Dec;50(12):1413-20.

86. Salvy S-J, Bowker JW, Roemmich JN, Romero N, Kieffer E, Paluch R, Epstein LH. Peer influence on childrens physical activity: An experience sampling study. J Pediatr Psychol. 2008;33(1):39-49.

87. Schöndube A, Kanning M, Fuchs R. The bidirectional effect between momentary affective states and exercise duration on a day level. Frontiers in Psychology. 2016 Sep; 7:1414.

88. Schöndube A, Bertrams A, Sudeck G, Fuchs R. Self-control strength and physical exercise: An ecological momentary assessment study. Psychol Sport Exerc. 2017 Mar;29:19-26.

89. Seto E, Hua J, Wu L, Bestick A, Shia V, Eom S, Han J, Wang M, Li Y. The Kunming CalFit study: modeling dietary behavioral patterns using smartphone data. Conf Proc . Annu Int Conf IEEE Eng Med Biol Soc IEEE Eng Med Biol Soc Annu Conf. 2014 
775

776

777

778

779

780

781

782

783

784

785

786

787

788

789

790

791

792

793

794

795

796

797

798

799

800

801

802

803

804

805

806

807

808

809

810

811

812

813

814

815

816

817

818

819

820

Aug;2014:6884-7.

90. Seto E, Hua J, Wu L, Shia V, Eom S, Wang M, Li Y. Models of Individual Dietary Behavior Based on Smartphone Data: The Influence of Routine, Physical Activity, Emotion, and Food Environment. Yao L, editor. PLoS One. 2016 Apr 6;11(4):e0153085.

91. Snippe E, Simons CJP, Hartmann JA, Menne-Lothmann C, Kramer I, Booij SH, Viechtbauer W, Delespaul P, Myin-Germeys I, Wichers M. Change in daily life behaviors and depression: Within-person and between-person associations. Health Psychol. 2016 May;35(5):433-41.

92. Soos I, Biddle S, Boros-Balint I, Sandor I, Szabo P, Hamar P, Simonek J. Prevalence of sedentary behaviour in young people in Romania and Slovakia. Eur Phys Educ Rev. 2012 Feb;18(1):19-46.

93. Soos I, Biddle SJH, Ling J, Hamar P, Sandor I, Boros-Balint I, Szabo P, Simonek J. Physical activity, sedentary behaviour, use of electronic media, and snacking among youth: An International study. Kinesiology. 2014;46(2):155-63.

94. Spook JE, Paulussen T, Kok G, Van Empelen P. Monitoring dietary intake and physical activity electronically: feasibility, usability, and ecological validity of a mobile-based Ecological Momentary Assessment tool. J Med Internet Res. 2013 Sep 24;15(9):e214.

95. Sternfeld B, Jiang S-F, Picchi T, Chasan-Taber L, Ainsworth B, Quesenberry Jr. CP. Evaluation of a Cell Phone-Based Physical Activity Diary. Med Sci Sports Exerc. 2012 Mar;44(3):487-95.

96. Thomas JG, Bond DS, Ryder BA, Leahey TM, Vithiananthan S, Roye GD, Wing RR. Ecological momentary assessment of recommended postoperative eating and activity behaviors. Surg Obes Relat Dis. 2011 Mar;7(2):206-12.

97. Timmerman JG, Dekker-van Weering MGH, Toenis TM, Hermens HJ, VollenbroekHutten MMR. Relationship between patterns of daily physical activity and fatigue in cancer survivors. Eur J Oncol Nurs. 2015;19(2):162-8.

98. von Haaren B, Loeffler SN, Haertel S, Anastasopoulou P, Stumpp J, Hey S, Boes K. Characteristics of the activity-affect association in inactive people: an ambulatory assessment study in daily life. Front Psychol. 2013;4.

99. Wichers M, Kasanova Z, Bakker J, Thiery E, Derom C, Jacobs N, van Os J. From Affective Experience to Motivated Action: Tracking Reward-Seeking and PunishmentAvoidant Behaviour in Real-Life. Dichter GS, editor. PLoS One. 2015 Jun 18;10(6): e0129722.

100. Williams DM, Dunsiger S, Emerson JA, Gwaltney CJ, Monti PM, Miranda R. Self-Paced Exercise, Affective Response, and Exercise Adherence: A Preliminary Investigation Using Ecological Momentary Assessment. J Sport Exerc Psychol. 2016 Jun;38(3):282-91.

101. McCormick BP, Frey G, Lee C, Chun S, Sibthorp J, Gajic T, Stamatovic-Gajic B, Maksimovich M. Predicting transitory mood from physical activity level among people with severe mental illness in two cultures. Int J Soc Psychiatry. 2008 Nov;54(6):527-38.

102. Salvy S-J, Bowker JW, Roemmich JN, Romero N, Kieffer E, Paluch R, Epstein LH. Peer influence on children's physical activity: an experience sampling study. J Pediatr Psychol. 2008;33(1):39-49.

103. Biddle SJH, Gorely T, Marshall SJ, Cameron N. The prevalence of sedentary behavior and physical activity in leisure time: a study of Scottish adolescents using ecological momentary assessment. Prev Med. 2009 Feb;48(2):151-5.

104. Rouse PC, Biddle SJH. An ecological momentary assessment of the physical activity and 
821

822

823

824

825

826

827

828

829

830

831

832

833

834

835

836

837

838

839

840

841

842

843

844

845

846

847

848

849

850

851

852

853

854

855

856

857

858

859

860

861

862

863

864

865

866 sedentary behaviour patterns of university students. Health Educ J. 2010 Mar;69(1):11625.

105. Lepage ML, Crowther JH. The effects of exercise on body satisfaction and affect. Body Image. 2010 Mar;7(2):124-30.

106. Serre F, Fatseas M, Swendsen J, Auriacombe M. Ecological momentary assessment in the investigation of craving and substance use in daily life: A systematic review. Drug Alcohol Depend. 2015 Mar 1;148:1-20.

107. Schueller SM, Aguilera A, Mohr DC. Ecological momentary interventions for depression and anxiety. Depress Anxiety. 2017 Jun;34(6):540-5.

108. Engel SG, Crosby RD, Thomas G, Bond D, Lavender JM, Mason T, Steffen KJ, Green DD, Wonderlich SA. Ecological Momentary Assessment in Eating Disorder and Obesity Research: a Review of the Recent Literature. Curr Psychiatry Rep. 2016 Apr 18;18(4):37.

109. Bruening M, van Woerden I, Todd M, Brennhofer S, Laska MN, Dunton G. A Mobile Ecological Momentary Assessment Tool (devilSPARC) for Nutrition and Physical Activity Behaviors in College Students: A Validation Study. J Med Internet Res. 2016 Jul 27;18(7):e209.

110. van Os J, Verhagen S, Marsman A, Peeters F, Bak M, Marcelis M, Drukker M1, Reininghaus U, Jacobs N, Lataster T, Simons C, ESM-MERGE Investigators PhD, Lousberg R, Gülöksüz S1, Leue C, Groot PC, Viechtbauer W, Delespaul P. The experience sampling method as an mHealth tool to support self-monitoring, self-insight, and personalized health care in clinical practice. Depress Anxiety. 2017 Jun;34(6):481-93.

111. Bagot KS, Matthews SA, Mason M, Squeglia LM, Fowler J, Gray K, Herting M, May A, Colrain I, Godino J, Tapert S, Brown S, Patrick K. Current, future and potential use of mobile and wearable technologies and social media data in the ABCD study to increase understanding of contributors to child health. Dev Cogn Neurosci. 2018 Aug;32:121-9.

112. Poscia A, Frisicale EM, Parente P, de Waure C, La Milia DI, Di Pietro ML. Study habits and technology use in Italian university students. Ann Ist Super Sanita. 2015;51(2):12630 .

113. World Health Organization 2018. Global action plan on physical activity 2018-2030. More Active People for a Healthy World. Available from: https://apps.who.int/iris/bitstream/handle/10665/272722/9789241514187-eng.pdf

114. Maher JP, Rebar AL, Dunton GF. Ecological Momentary Assessment Is a Feasible and Valid Methodological Tool to Measure Older Adults' Physical Activity and Sedentary Behavior. Front Psychol. 2018 Aug 15;9:1485.

115. Patrick K, Griswold WG, Raab F, Intille SS. Health and the Mobile Phone. Am J Prev Med. 2008 Aug;35(2):177-81.

116. Myin-Germeys I, Kasanova Z, Vaessen T, Vachon H, Kirtley O, Viechtbauer W, Reininghaus U. Experience sampling methodology in mental health research: new insights and technical developments. World Psychiatry. 2018 Jun;17(2):123-32.

117. Ouchi Y, Rakugi H, Arai H, Akishita M, Ito H, Toba K, Kai I, Joint Committee of Japan Gerontological Society (JGLS) and Japan Geriatrics Society (JGS) on the definition and classification of the elderly. Redefining the elderly as aged 75 years and older: Proposal from the Joint Committee of Japan Gerontological Society and the Japan Geriatrics Society. Geriatr Gerontol Int. 2017 Jul;17(7):1045-7.

118. Fouad MN, Johnson RE, Nagy MC, Person SD, Partridge EE. Adherence and retention in clinical trials: a community-based approach. Cancer. 2014 Apr 1;120 Suppl 7:1106-12. 
867

868

869

870

871

872

873

874

875

876

877

878

879

880

881

882

883

884

885

886

887

888

889

890

891

892

893

894

895

896

897
119. World Health Organization. Global action plan on physical activity 2018-2030: more active people for a healthier world. 2018. $104 \mathrm{p}$.

120. Pacifico Silva H, Lehoux P, Miller FA, Denis J-L. Introducing responsible innovation in health: a policy-oriented framework. Heal Res Policy Syst. 2018 Dec 10;16(1):90.

121. Mikkelsen K, Stojanovska L, Polenakovic M, Bosevski M, Apostolopoulos V. Exercise and mental health. Maturitas. 2017 Dec;106:48-56.

122. Gustavson K, von Soest T, Karevold E, Røysamb E. Attrition and generalizability in longitudinal studies: findings from a 15-year population-based study and a Monte Carlo simulation study. BMC Public Health. 2012 Dec 29;12(1):918.

123. Carmona-Bayonas A, Jimenez-Fonseca P, Fernández-Somoano A, Álvarez-Manceñido F, Castañón E, Custodio A, de la Peña FA, Payo RM. Top ten errors of statistical analysis in observational studies for cancer research. Clin Transl Oncol. 2018 Aug 7;20(8):954-65.

124. Parrado E, Cervantes JC, Ocaña M, Pintanel M, Valero M and Capdevila L. Evaluación de la conducta activa: El registro semanal de actividad física (RSAF). Revista de Psicología del Deporte. 2009;18(2).

125. Dunton GF. Ecological Momentary Assessment in Physical Activity Research. Exerc Sport Sci Rev. 2017;45(1):48-54.

126. World Health Organization. Depression and Other Common Mental Disorders Global Health Estimates. 2017.

127. Chin S-H, Kahathuduwa CN, Binks M. Physical activity and obesity: what we know and what we need to know. Obes Rev. 2016 Dec;17(12):1226-44.

128. Kip H, Bouman YHA, Kelders SM, van Gemert-Pijnen LJEWC. eHealth in Treatment of Offenders in Forensic Mental Health: A Review of the Current State. Front psychiatry. 2018 Feb 21;9:42.

129. Hurt K, Walker RJ, Campbell JA, Egede LE. mHealth Interventions in Low and MiddleIncome Countries: A Systematic Review. Glob J Health Sci. 2016 Jan 1;8(9):54429.

130. Chung LMY, Law QPS, Fong SSM, Chung JWY, Yuen PP. A cost-effectiveness analysis of teledietetics in short-, intermediate-, and long-term weight reduction. J Telemed Telecare. 2015 Jul 10;21(5):268-75. 


\section{Table $\mathbf{1}$ (on next page)}

Inclusion criteria and description for this review.

EMA: Ecological Momentary Assessment; PA: Physical Activity. 
1 Table 1. Inclusion criteria for this review.

\section{Criteria}

1) EMA has to accomplish the following points:

\section{Description}

a) Instruments that collect data in real time. Participants reported the activities and/or behaviors, moods, etc. at the moment they are experiencing them or up to 24 hours, after the activity was carried out.

b) In a natural environment.

c) Repeated measures ( 2 or more measures).

d) Self-reports and/or automatic recordings.

e) Using both electronic devices and/or paper and pencil format.

2) PA is considered: PA has to be spontaneous or planned activity, carried out individually or collectively and that incorporates a physical effort component of any intensity.

3) Type of article: All articles that provide original data on the use of EMA in PA (criteria 1 and 2) and are published in a scientific journal without taking into account the type and number of sample as well as the experimental design. 


\section{Table 2 (on next page)}

General characteristics of reviewed studies about ecological momentary assessment (EMA) in physical activity (PA).

Hu: Hungary; UK: United Kingdom; Slo: Slovenia; Ro: Romania; Ser: Serbia, Chi: China; US:

University students L: Longitudinal; P: Prognostic; NI: No intervention; CG: Control group; QE:

Quasi Experimental; R: Randomization; *: with physical diseases or psychological disorders. 


\section{Table 2. General characteristics of reviewed studies about ecological momentary assessment 2 (EMA) in physical activity (PA).}

\begin{tabular}{|c|c|c|c|c|}
\hline Reference, year, country & Study population & $\mathrm{n}$ (males) & Age & Design \\
\hline (27), Aggio et al., 2017, England & US & $51(26)$ & $24.0 \pm 4.7$ & $\mathrm{~L}, \mathrm{P}, \mathrm{NI}$ \\
\hline (28), Basen-Engquist et al., 2013, USA & Women Endometrial Cancer Survivor* & $79(0)$ & $57.0 \pm 11.01$ & $\mathrm{~L}, \mathrm{P}, \mathrm{NI}$ \\
\hline [27], Biddle et al., 2009, Hun, Slo, Ro & Adolescents & $623(247)$ & $15.5 \pm 0.9$ & $\mathrm{~L}, \mathrm{P}, \mathrm{NI}$ \\
\hline [28], Biddle et al., 2009, UK & Adolescents & $1484(561)$ & $14.67 \pm 0.92$ & $\mathrm{~L}, \mathrm{P}, \mathrm{NI}$ \\
\hline [29], Biddle et al., 2009, UK & Adolescents & $1493(566)$ & 14.8 & $\mathrm{~L}, \mathrm{P}, \mathrm{NI}$ \\
\hline (32), Biddle et al., 2009, Scotland & Adolescents & $991(385)$ & 14.1 & $\mathrm{~L}, \mathrm{P}, \mathrm{NI}$ \\
\hline (33), Bohnert et al., 2013, USA & Adolescents & $25(9)$ & $12.6 \pm 1.0$ & $\mathrm{~L}, \mathrm{P}, \mathrm{NI}$ \\
\hline (34), Bond et al., 2013, USA & Bariatric Surgery Patients* & $21(4)$ & $48.5 \pm 2.8$ & $\mathrm{~L}, \mathrm{P}, \mathrm{NI}$ \\
\hline (35), Bonham et al., 2018, England & Adults (Recreational Runners) & $38(20)$ & $18-49$ & $\mathrm{~L}, \mathrm{P}, \mathrm{NI}$ \\
\hline [34], Bossmann et al, 2013, Germany & US & $62(53)$ & $21.4 \pm 1.8$ & $\mathrm{~L}, \mathrm{P}, \mathrm{NI}$ \\
\hline (37), Brannon et al., 2016, USA & Adolescents & $20(12)$ & $15.67 \pm 1.75$ & L, P, NI \\
\hline (38), Burg et al., 2017, USA & Adults (eager to became active) & $63(27)$ & $31.9 \pm 9.5$ & $\mathrm{~L}, \mathrm{E}, \mathrm{CG}, \mathrm{R}$ \\
\hline [37], Cabrita et al., 2017, Netherlands & Older adults & $10(4)$ & $68.7 \pm 5.5$ & $\mathrm{~L}, \mathrm{P}, \mathrm{NI}$ \\
\hline (40), Conroy et al., 2013, USA & US & $128(53)$ & $21.3 \pm 1.1$ & $\mathrm{~L}, \mathrm{P}, \mathrm{NI}$ \\
\hline [39], Dunton et al., 2011, USA & Children & $121(62)$ & $9-13$ & $\mathrm{~L}, \mathrm{P}, \mathrm{NI}$ \\
\hline [40], Dunton et al., 2012, USA & Children & $108(59)$ & 11 & $\mathrm{~L}, \mathrm{P}, \mathrm{NI}$ \\
\hline [41], Dunton et al., 2012, USA & Children & $94(49)$ & $9-13$ & $\mathrm{~L}, \mathrm{QE}, \mathrm{CG}$ \\
\hline [42], Dunton et al., 2012, USA & Adults & $110(30)$ & $40.4 \pm 9.74$ & $\mathrm{~L}, \mathrm{P}, \mathrm{NI}$ \\
\hline [43], Dunton et al., 2014, USA & Children & $114(56)$ & $9-13$ & L, P, NI \\
\hline [44], Dunton et al., 2015, USA & Adults & $116(32)$ & $40.5 \pm 9.5$ & $\mathrm{~L}, \mathrm{P}, \mathrm{NI}$ \\
\hline [45], Dunton et al., 2016, USA & Adolescents & $39(18)$ & $15.9 \pm 1.2$ & $\mathrm{~L}, \mathrm{P}, \mathrm{NI}$ \\
\hline (48), Elavsky et al., 2016, USA & Women (Peri-post menopausal) & $121(0)$ & 51.5 & $\mathrm{~L}, \mathrm{P}, \mathrm{NI}$ \\
\hline (49), Emerson et al., 2018, USA & Adults (Low-Active and Obese)* & $59(7)$ & $47.71 \pm 11.06$ & $\mathrm{~L}, \mathrm{E}, \mathrm{CG}, \mathrm{R}$ \\
\hline (50), Fanning et al., 2016, USA & US & $33(9)$ & $20.5 \pm 1.5$ & $\mathrm{~L}, \mathrm{P}, \mathrm{NI}$ \\
\hline (51), Fortier et al., 2015, Canada & Women (Physically active Mothers) & $63(0)$ & $42.6 \pm 5.61$ & $\mathrm{~L}, \mathrm{P}, \mathrm{NI}$ \\
\hline (52), Fuller et al., 2013, Australia & Adult Women & $37(0)$ & $34.05 \pm 9.73$ & $\mathrm{~L}, \mathrm{P}, \mathrm{NI}$ \\
\hline [51], Gorely et al., 2009, UK & Adolescents & $1171(477)$ & $14.8 \pm 0.86$ & $\mathrm{~L}, \mathrm{P}, \mathrm{NI}$ \\
\hline (54), Gorely et al., 2009, UK & Adolescent boys & $561(561)$ & $14.6 \pm 0.89$ & $\mathrm{~L}, \mathrm{P}, \mathrm{NI}$ \\
\hline (55), Hager et al., 2017, USA & Mother-Toddler Dyads & $160(0)$ & 26.6 & $\mathrm{~L}, \mathrm{P}, \mathrm{NI}$ \\
\hline (56), Hausenblas et al., 2008 & US & $40(14)$ & $20.5 \pm 2.5$ & $\mathrm{~L}, \mathrm{E}, \mathrm{R}$ \\
\hline (57), Heininga et al., 2017, Netherlands & Adults (with or without anhedonia)* & $138(28)$ & 21.48 & $\mathrm{~L}, \mathrm{P}, \mathrm{NI}$ \\
\hline (58), Hekler et al., 2012, USA & Adults & $14(7)$ & $59.4 \pm 6.4$ & $\mathrm{~L}, \mathrm{P}, \mathrm{NI}$ \\
\hline (59), Hyde et al., 2011, USA & US & $190(65)$ & $19.3 \pm 2.8$ & $\mathrm{~L}, \mathrm{P}, \mathrm{NI}$ \\
\hline (60), Jones et al., 2017, USA & Adults (stressed)* & $105(29)$ & $40.3 \pm 9.8$ & $\mathrm{~L}, \mathrm{P}, \mathrm{NI}$ \\
\hline (61), Kanning et al., 2015, Germany & Older adults & $69(35)$ & $60.1 \pm 7.1$ & $\mathrm{~L}, \mathrm{P}, \mathrm{NI}$ \\
\hline (62), Kanning \& Schoebi 2016, Germany & US & $65(28)$ & $24.6 \pm 3.2$ & L, P, NI \\
\hline (63), Kanning \& Hansen 2017, Germany & Older adults & $68(35)$ & $60.1 \pm 7.1$ & $\mathrm{~L}, \mathrm{P}, \mathrm{NI}$ \\
\hline (64), Kim et al., 2014, Japan & Depressive patients and healthy adults* & $57(55)$ & 37.35 & L, P, NI, CG \\
\hline (65), Knell et al., 2017, USA & Adults & $238(78)$ & 43.3 & $\mathrm{~L}, \mathrm{P}, \mathrm{NI}$ \\
\hline
\end{tabular}


[63], LePage et al., 2012, USA

Study1

Study2

[64], LePage \& Crowther, 2010 USA

(68), Liao et al., 2014, USA

(69), Liao et al., 2015, USA

(70), Liao et al., 2017, USA

[68], Liao et al., 2017, USA

[69], Liao, et al., 2017, USA

(73), Maher et al., 2014, USA

(74), Maher et al., 2016, USA

(75), Marquet et al., 2017, USA

(76), Marquet et al., 2018, USA

(77), Mata et al., 2012, USA

[75] McCormick et al., 2008, USA and Ser

[76] McCormick et al., 2009, USA and Ser

(80), Nadell et al., 2015, USA

(81), O'Connor et al., 2017, USA

(82), Pickering et al., 2016, USA

[80], Rouse \& Biddle 2010, England

(84), Rusby et al., 2014, USA

(85), Sala et al., 2017, USA

(86), Salvy et al., 2018, USA

(87), Shondube et al., 2016, Germany

(88), Shondube et al., 2017, Germany

(89), Seto et al., 2014, China

(90), Seto, et al., 2016, China

(91), Snippe et al., 2016, Netherlands

(92), Soos et al., 2012, Ro and Slo

(93), Soos et al., 2014, UK, Hu, Ro, Slo, Chi

(94), Spook et al., 2013, Netherlands

(95), Sternfeld et al., 2012, USA

Pilot

Validation

(96), Thomas et al., 2011, USA

(97), Timmerman et al., 2015, Netherlands

(98), von Haaren et al., 2013, Germany

(99), Witchers et al., 2015, Belgium

(100), Williams et al., 2016, USA

$$
3
$$

4

5
US

US with eating disorders*

US (with body dissatisfaction)

Children and Adolescents

Adults

Adults

Adults (dog owners)

Adults

US

Adults

US (players of Pokemon Go)

US (players of Pokemon Go)

Adults with depression and controls*

Adults with severe mental illness*

Adults with severe mental illness*

Adults (Tabacoo smokers)

Mother Children Dyads

Adults

US

Adolescents

US with eating disorders*

Adolescents (overweight)

US

US

US and their friends

US

Depressive patients*

Adolescents

Adolescents

Adolescents and Adults

Adults

Adults

Gastric patients*

Cancer Survivors*

US

Women (Twins)

Sedentary and obese adults

\begin{tabular}{|c|c|c|}
\hline $51(0)$ & $19.06 \pm 3.10$ & L, P, NI \\
\hline $76(0)$ & $19.08 \pm 2.86$ & $\mathrm{~L}, \mathrm{P}, \mathrm{NI}, \mathrm{CG}$ \\
\hline $54(0)$ & $19.1 \pm 2.88$ & L, P, NI, CG \\
\hline $120(62)$ & $9-13$ & L, P, NI \\
\hline $114(30)$ & $27-73$ & L, P, NI \\
\hline $82(22)$ & 39.8 & L, P, NI \\
\hline $71(17)$ & $40.2 \pm 8.6$ & L, P, NI \\
\hline $110(30)$ & $40.4 \pm 9.74$ & L, P, NI \\
\hline $128(53)$ & $21.3 \pm 1.1$ & $\mathrm{~L}, \mathrm{P}, \mathrm{NI}$ \\
\hline $90(30)$ & $40.3 \pm 9.6$ & L, P, NI \\
\hline 47 (24) & 19.45 & L, P, NI \\
\hline 74 (37) & 19.6 & $\mathrm{~L}, \mathrm{P}, \mathrm{NI}$ \\
\hline $106(32)$ & 26.8 & L, P, NI, CG \\
\hline $22(12)$ & 38.95 & L, P, NI \\
\hline 22 (Not inf) & Not inf & L, P, NI \\
\hline $188(88)$ & $21.32 \pm 0.77$ & L, P, NI \\
\hline $175(84)$ & 41.1 & L, P, NI \\
\hline $103(30)$ & $40.3 \pm 9.6$ & L, P, NI \\
\hline $84(46)$ & 19.85 & $\mathrm{~L}, \mathrm{P}, \mathrm{NI}$ \\
\hline $82(40)$ & Not inf & L, P, NI \\
\hline $129(0)$ & $19.19 \pm 1.40$ & L, P, NI \\
\hline $20(10)$ & 13.52 & L, P, NI, CG \\
\hline $60(20)$ & $23.5 \pm 2.8$ & L, P, NI \\
\hline $63(21)$ & $23.5 \pm 2.8$ & L, P, NI \\
\hline 12 (Not inf) & $18-31$ & L, P, NI \\
\hline $12(4)$ & $24.6 \pm 3.06$ & L, P, NI \\
\hline $85(47)$ & $48 \pm 10.2$ & $\mathrm{~L}, \mathrm{E}, \mathrm{CG}, \mathrm{R}$ \\
\hline $635(251)$ & $16 \pm 1.0$ & L, P, NI \\
\hline $812(348)$ & $15.6 \pm 1.0$ & $\mathrm{~L}, \mathrm{P}, \mathrm{NI}$ \\
\hline $30(13)$ & $16-21$ & L, P, NI \\
\hline- & - & - \\
\hline $33(23)$ & $55.6 \pm 8.8$ & L, P, NI \\
\hline 345 (296) & $56.9 \pm 5.7$ & L, P, NI \\
\hline $21(4)$ & $48.5 \pm 12.6$ & L, P, NI \\
\hline $36(12)$ & 55.95 & L, P, NI, CG \\
\hline 29 (Not inf) & $21.3 \pm 1.7$ & L, P, NI \\
\hline $504(0)$ & $27 \pm 7.6$ & $\mathrm{~L}, \mathrm{P}, \mathrm{NI}$ \\
\hline $59(7)$ & $47.7 \pm 11.1$ & $\mathrm{~L}, \mathrm{E}, \mathrm{CG}, \mathrm{R}$ \\
\hline
\end{tabular}

$19.06 \pm 3.10$ - 
6 Hu: Hungary; UK: United Kingdom; Slo: Slovenia; Ro: Romania; Ser: Serbia, Chi: China; US: University students 7 L: Longitudinal; P: Prognostic; NI: No intervention; CG: Control group; QE: Quasi Experimental; R: Randomization; $8 \quad *$ : with physical diseases or psychological disorders. 


\section{Table 3 (on next page)}

Table 3. Characteristics of the main methodological aspects of EMA.

Study duration column: d: days. Day period column: Sat: Saturday, Tu: Tuesday, Mo: Monday, Fri: Friday. Prompts per day column: h: hours, m: minutes, a x d: assessment per day, Ran: Random. EMA named column: ESM: Experienced Sampling Method, NS: Naturalistic Study, AA: Ambulatory Assessment, ES: Experience Sampling, CS-EMA: Context-Sensitive EMA, DDM/ES: Daily Diary Method or Experience Sampling. EMA instruments and sensors columns: mHealth (includes: Smartphone; iPod, Video Recording; Automatized call survey; SMS), PDA: Personal Digital Assistant or similar apparatus like watch-type computer, OSS: Online Survey System, P\&P: Paper and Pencil, ACC: Accelerometers, GPS: Global Positioning System, HRCHB: Heart rate Chest Band. Topic column: BMI: Body Mass Index, ISD: Income and Socio Demographics, GA: General Activity (included: sedentary behavior, time with the smartphone, time reading, eating, active traveling), PS: Psychological State, BPA: Barriers to Physical Activity, SLP: Sleep, EB: Eating Behavior, SC: Social Context, EC: Environmental Context, OV: Other Variables (included: self-efficacy, type of country, arousal, acceptability, safety, traffic, use of smartphone during exercise, toddler with mother, waist circumference, autonomic, competencies, vegetation, cultural variables and body perceptions, amount of garbage, energy and fatigue). 
1 Table 3. Characteristics of the main methodological aspects of EMA

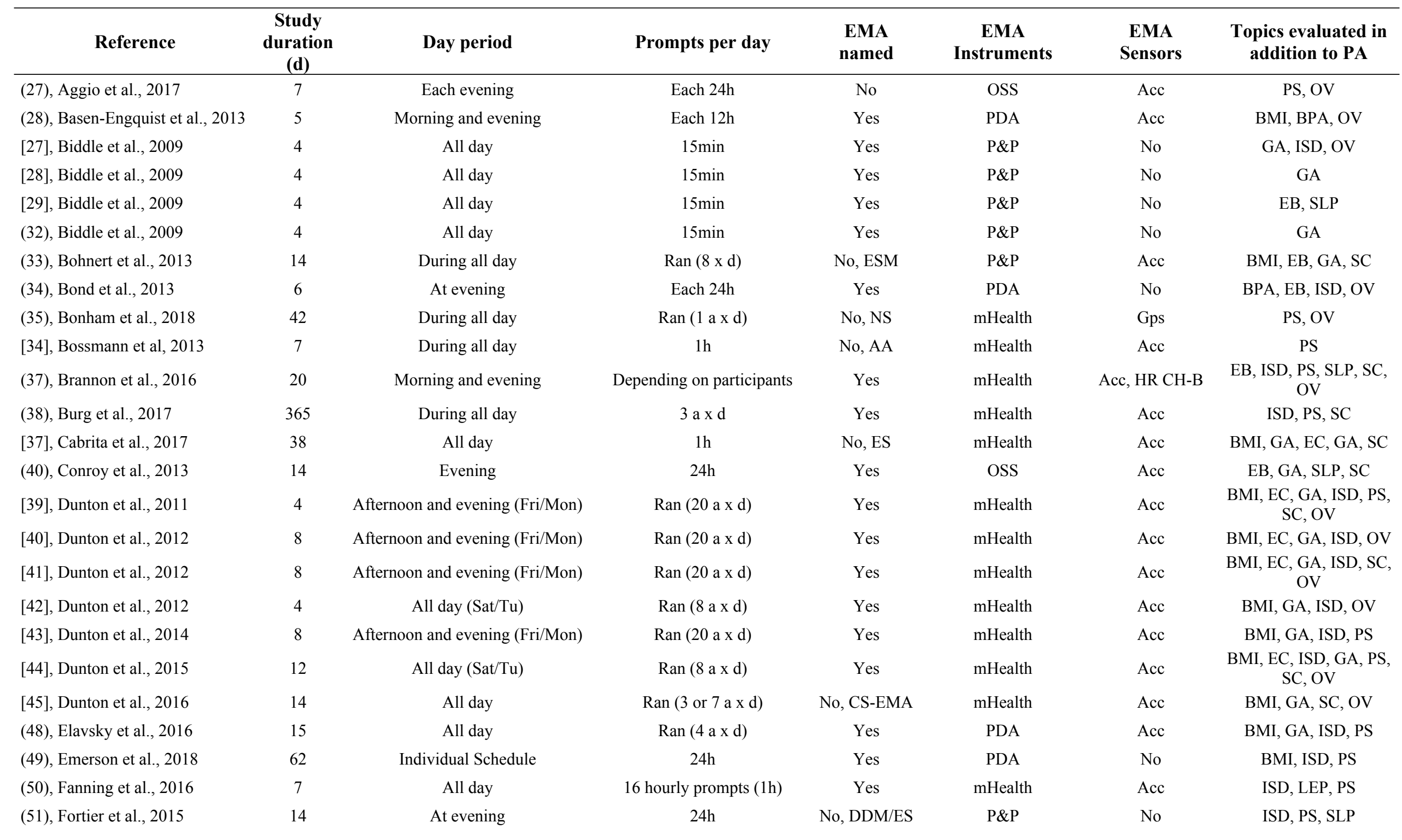




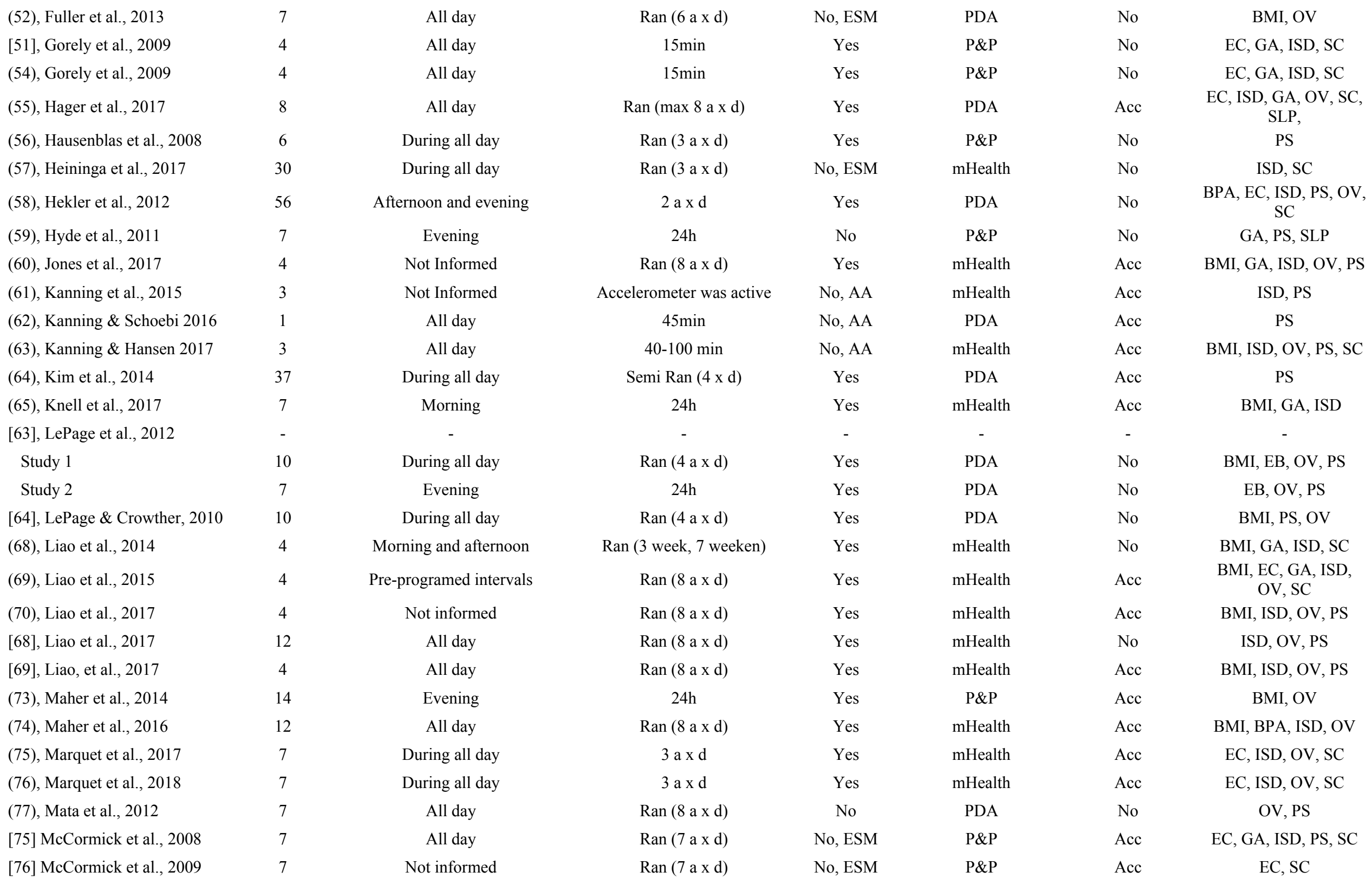




\begin{tabular}{|c|c|c|c|c|c|c|c|}
\hline (80), Nadell et al., 2015 & 7 & Not informed & $\operatorname{Ran}(5-7$ a x d) & Yes & PDA & No & BMI, ISD, OV PS \\
\hline (81), O’Connor et al., 2017 & 8 & During all day & Ran (week 3/4, weekend 7/8) & Yes & mHealth & No & BMI, EB, ISD, OV \\
\hline (82), Pickering et al., 2016 & 4 & All day & $\operatorname{Ran}(8 \mathrm{a} \times \mathrm{d})$ & Yes & mHealth & Acc & $\begin{array}{c}\text { BMI, BPA, EC, ISD, } \\
\text { OV }\end{array}$ \\
\hline (84), Rusby et al., 2014 & 28 & During all day & $\operatorname{Ran}(3-6$ a $\times d)$ & Yes & mHealth & No & GA, ISD, PS, SC \\
\hline (85), Sala et al., 2017 & 7 & Personalized for participants & $\operatorname{Ran}(4 \mathrm{a} x \mathrm{~d})$ & Yes & mHealth & No & $\mathrm{EB}, \mathrm{OV}, \mathrm{PS}$ \\
\hline (86), Salvy et al., 2018 & 7 & All day & $2 \mathrm{~h}$ & No, ESM & PDA & No & BMI, SC \\
\hline (87), Shondube et al., 2016 & 20 & During all day & $\operatorname{Ran}(4$ a x d) & Yes & mHealth & No & ISD, PS \\
\hline (88), Shondube et al., 2017 & 20 & During all day & $\operatorname{Ran}(4$ a x d) & Yes & mHealth & No & ISD, OV \\
\hline (89), Seto et al., 2014 & 7 & Not informed & Each meal & Yes & mHealth & GPS, Acc & $\mathrm{EB}, \mathrm{EC}, \mathrm{PS}$ \\
\hline (90), Seto, et al., 2016 & 14 & Not informed & $\operatorname{Ran}(5 \mathrm{a} x \mathrm{~d})$ & Yes & mHealth & GPS, Acc & $\begin{array}{c}\text { BMI, EB, EC, ISD, PS, } \\
\text { OV, SC, SLP }\end{array}$ \\
\hline (91), Snippe et al., 2016 & 12 & All day & Semi Ran $(10$ a x d $)$ & No, ESM & mHealth & No & GA, ISD, PS, SC \\
\hline (92), Soos et al., 2012 & 4 & All day & $15 \mathrm{~min}$ (the end of day) & Yes & $\mathrm{P} \& \mathrm{P}$ & No & $\mathrm{EC}, \mathrm{GA}, \mathrm{ISD}, \mathrm{SC}$ \\
\hline (94), Spook et al., 2013 & 7 & During all day & $\operatorname{Ran}(5 \mathrm{a} x \mathrm{~d})$ & Yes & mHealth & No & $\begin{array}{c}\mathrm{BPA}, \mathrm{EC}, \mathrm{GA}, \mathrm{OV}, \mathrm{PS} \text {, } \\
\text { SC }\end{array}$ \\
\hline (95), Sternfeld et al., 2012 & - & - & - & - & - & - & - \\
\hline Pilot & 12 & During all day & $3 \mathrm{axd}$ & No & mHealth, P\&P & No & BMI, GA, ISD \\
\hline Validation & 14 & During all day & $3 \mathrm{axd}$ & No & mHealth & Acc & BMI, GA, ISD \\
\hline (96), Thomas et al., 2011 & 6 & All day & Semi Ran (6 a x d) & Yes & PDA & No & BMI, EB, GA, ISD, \\
\hline (97), Timmerman et al., 2015 & 5 & During all day & $3(13: 00,17: 00,20: 00)$ & No, AA & mHealth & Acc & BMI, ISD, OV \\
\hline (98), von Haaren et al., 2013 & 2 & During all day & $2 \mathrm{~h}$ a little bit Ran & No, AA & PDA & Acc & BMI, PS \\
\hline (99), Witchers et al., 2015 & 5 & All day & Semi Ran $(10$ a x d $)$ & No, ESM & $P \& P$ & No & GA, ISD, PS, OV \\
\hline (100), Williams et al., 2016 & 42 & All day & $12 \times \mathrm{d}$ & Yes & PDA & No & BMI, ISD, PS \\
\hline
\end{tabular}

3 Study duration column: d: days. Day period column: Sat: Saturday, Tu: Tuesday, Mo: Monday, Fri: Friday. Prompts per day column: h: hours, m: minutes, a x d: assessment per day, Ran: Random. EMA named column: ESM: Experienced Sampling Method, NS: Naturalistic Study, AA: Ambulatory Assessment, ES: Experience Sampling, CS-EMA: Context-Sensitive EMA, DDM/ES: Daily Diary Method or Experience Sampling. EMA instruments and sensors columns: mHealth (includes: Smartphone; iPod, Video Recording; Automatized call survey; SMS), PDA: Personal Digital Assistant or similar apparatus like watch-type computer, OSS: Online Survey System, P\&P: Paper and Pencil, ACC: Accelerometers, GPS: Global Positioning System, HRCH-B: Heart rate Chest Band. Topic 8 column: BMI: Body Mass Index, ISD: Income and Socio Demographics, GA: General Activity (included: sedentary behavior, time with the smartphone, time 
9 reading, eating, active traveling), PS: Psychological State, BPA: Barriers to Physical Activity, SLP: Sleep, EB: Eating Behavior, SC: Social Context, EC: 10 Environmental Context, OV: Other Variables (included: self-efficacy, type of country, arousal, acceptability, safety, traffic, use of smartphone during exercise,

11 toddler with mother, waist circumference, autonomic, competencies, vegetation, cultural variables and body perceptions, amount of garbage, energy and fatigue). 


\section{PeerJ}


Figure 1

PRISMA flow diagram with the different previous phases to the qualitative synthesis. 







\section{Figure 2}

Other topics or target variables reported in the reviewed studies, different from the behavior of PA.

Psychological state includes: affection, emotions, depression, stress and anxiety. General activity includes: sedentary behavior, time with the smartphone, time reading, eating, active traveling, etc

\section{Topics}






\section{Figure 3}

Risk of bias (RoB) of the reviewed studies expressed by the number of studies.

A) Risk of bias of prognostic studies (NICE tool). Representativeness: the study sample represents the population of interest with regard to key characteristics; Loss to follow-up is unrelated to key characteristics; Outcome is adequately measured in study participants; Confounding: important potential confounders are appropriately accounted for limiting potential bias with respect to the prognostic factor of interest. B) Risk of bias of experimental and quasi-experimental studies (Cochrane tools). Random allocation: random sequence generation; Allocation concealment; Blinding of participants and personnel; Outcome: blinding of outcomes assessment; Missing data: incomplete outcome data. 


\section{A. Risk of bias of prognostic studies}

(NICE tool)
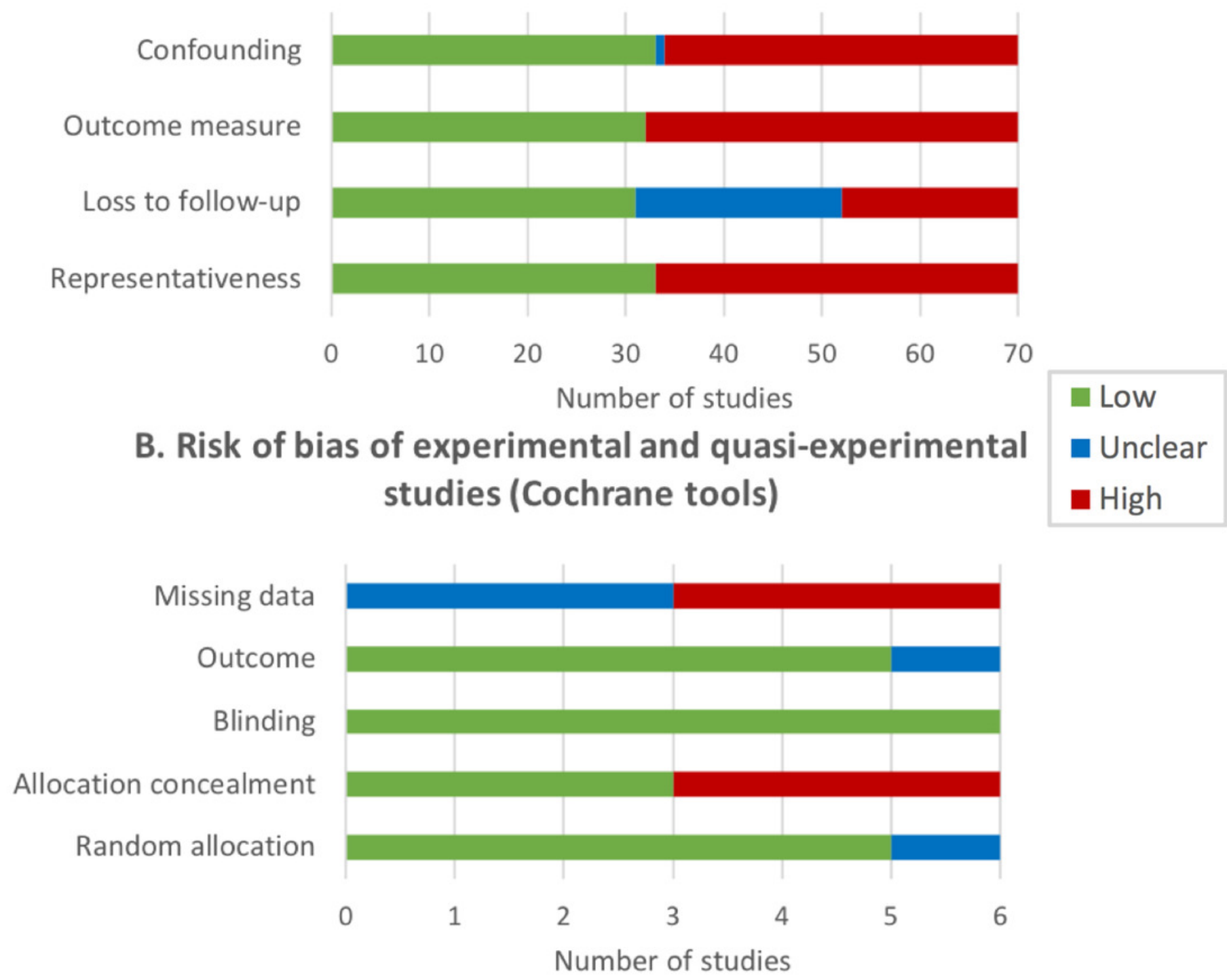